Article

\title{
An investigation of uniaxial mechanical properties of excised sheep heart muscle fibre - fitting of different hyperelastic constitutive models
}

\author{
Fulufhelo Nemavhola ${ }^{a^{*}}$, Harry Ngwangwaa, Thanyani Pandelani ${ }^{b}$
}

\author{
aUnisa Biomechanics Research Lab, Department of Mechanical Engineering, School of Engineering, College of Science \\ Engineering and Technology, University of South Africa, Pretoria 0001, South Africa. \\ ${ }^{b}$ Council of Scientific and Industrial Research (CSIR), PO Box 395, Pretoria 0001, South Africa.
}

\begin{abstract}
This paper presents the investigation of biomechanical behaviour of sheep heart fibre using uniaxial tests in various samples. Non-linear Finite Element models (FEA) that are utilised in understanding mechanisms of different diseases may not be developed without the accurate material properties. This paper presents uniaxial mechanical testing data of the sheep heart fibre. The mechanical uniaxial data of the heart fibre was then used in fitting four constitutive models including the Fung model, Polynomial (Anisotropic), Holzapfel (2005) model, Holzapfel (2000) model and the Four-fibre Family model. Even though the constitutive models for soft tissues including heart myocardium have been presented over several decades, there is still a need for accurate material parameters from reliable hyperelastic constitutive models. Therefore, the aim of this research paper is to select five hyperelastic constitutive models and fit experimental data in the uniaxial experimental data of the sheep heart fibre. A fitting algorithm was made used to optimally fitting and determination of the material parameters based on selected hyperelastic constitutive model. In this study, the evaluation index (EI) was used to measure the performance and capability of each selected anisotropic hyperelatic model. It was observed that the best predictive capability of the mechanical behaviour of sheep heart fibre the Polynomial (anisotropic) model has the EI of 100 and this means that it is the best performance when compared to all the other models.
\end{abstract}

Keywords: Uniaxial testing, tissue mechanics, cardiac mechanics, tensile testing

\section{Introduction}

Biological tissues are often regarded as soft composite materials with complex alignment of fibres. Studying the biomechanical response of soft tissue including that of the myocardium is an active research [1-7]. The myocardium is a very complex and multiscale tissue whose mechanical behaviour is influenced by both active and passive processes. Therefore, a complete modelling of the myocardium is a very demanding exercise. Finite element analysis (FEA) has been utilised successfully in the improvement of designs and enhancement of the reliability of the systems, and it has therefore been applied to modelling of the myocardium. FEA has also been widely used in studying 
various mechanisms of diseases including cardiovascular diseases [8-14]. However, the myocardium presents an extra difficulty in that it undergoes significant structural and biomechanical changes in patients with heart diseases [15]. Therefore, the development of such advanced computational models heavily depends on the detailed mechanical properties of soft tissues which themselves are heavily reliant on the comprehensiveness of the experimental data for detailed parameter estimation in specific functional forms [16]. With large deformation, numerous hyperelastic constitutive models in predicting the mechanical behaviour of the soft tissues have been developed.

Nonlinear finite element analysis is commonly utilised for detailed structural analysis of complex soft tissue. It has been observed that with accurate material parameters derived from reliable strain energy functions of soft tissues, the numerical results may be compromised. Even though the constitutive models for soft tissues including the heart myocardium have been presented over a number of decades, there is still a need for accurate material parameters from reliable hyperelastic constitutive models. Therefore, the aim of this research paper is to select five hyperelastic constitutive models and fit experimental data in the uniaxial experimental data of the sheep heart fibre. A fitting algorithm was utilised to optimally fitting and determination of the material parameters. In this study, the evaluation index (EI) was utilised to measure the performance and capability of each selected anisotropic hyperelastic model.

Uniaxial testing remains the most common modality of mechanical analysis for biological and other soft materials. However, biaxial testing enables a more comprehensive understanding of these materials' mechanical behaviour [17]. This is because the heart myocardium is orthotropic material having three mutually orthogonal planes with distinct material properties, which obviously translate into different mechanical responses. Therefore, the uniaxial test data is not sufficient to model accurately the passive mechanical behaviour of the myocardium tissue.

Although rodents have predominantly been used for pre-clinical investigations of stem cells for repairing damaged myocardium, larger animals such as sheep have cardiac circulation closely resembling that of humans. As a result, sheep tissue has been used in medicine as a model in understanding various diseases due to size, physiological and functional comparisons. The availability of sheep tissues is also the main reason why it is used for understanding the passive mechanical properties.

Continuum mechanics and biomedical engineering research have huge interest in studying the mechanical behaviour of soft tissues through constitutive modelling [18]. In responding to how the myocardium behaves under mechanical forces, several anisotropic hyperelastic models were developed. Holzapfel and Ogden [12] classified the constitutive models for the myocardium into two, namely transversely isotropic and orthotropic models. However, there is an ongoing effort to develop more models for understanding the passive mechanical behaviour of the myocardium. Hyperelastic models have been utilised to study the accuracy based on the collected experimental biaxial tension and uniaxial compression. The Fung model is a widely utilised hyperelastic model which was originally developed for artery tissues. This hyperelastic model uses the strain energy 
function that depends on exponential function. Recently, a comparative study was presented for unfilled and highly filled rubbers using hyperelastic constitutive models [19].

The aim of this study is to use uniaxial test data of the sheep muscle fibre to generate material parameters for application to five different hyperelastic constitutive models. The Hyperfit ${ }^{\circledR}$ was utilised in determining the material parameters and errors associated with fitting selected constitutive models. These material parameters could be utilised in the future for the development of computational models in understanding how myocardial infarction affects the global functioning of the heart.

\section{Materials and Methods}

\subsection{Tissue acquisition and preparation}

The fresh sheep hearts were collected from the local abattoir (See Figure 1(a)). The hearts were then placed in the cooler box before transportation to the Biomechanics Lab for preparation and testing. The muscle fibre was then isolated and taken out from the left ventricle (LV) as shown in Figure 1 (b).

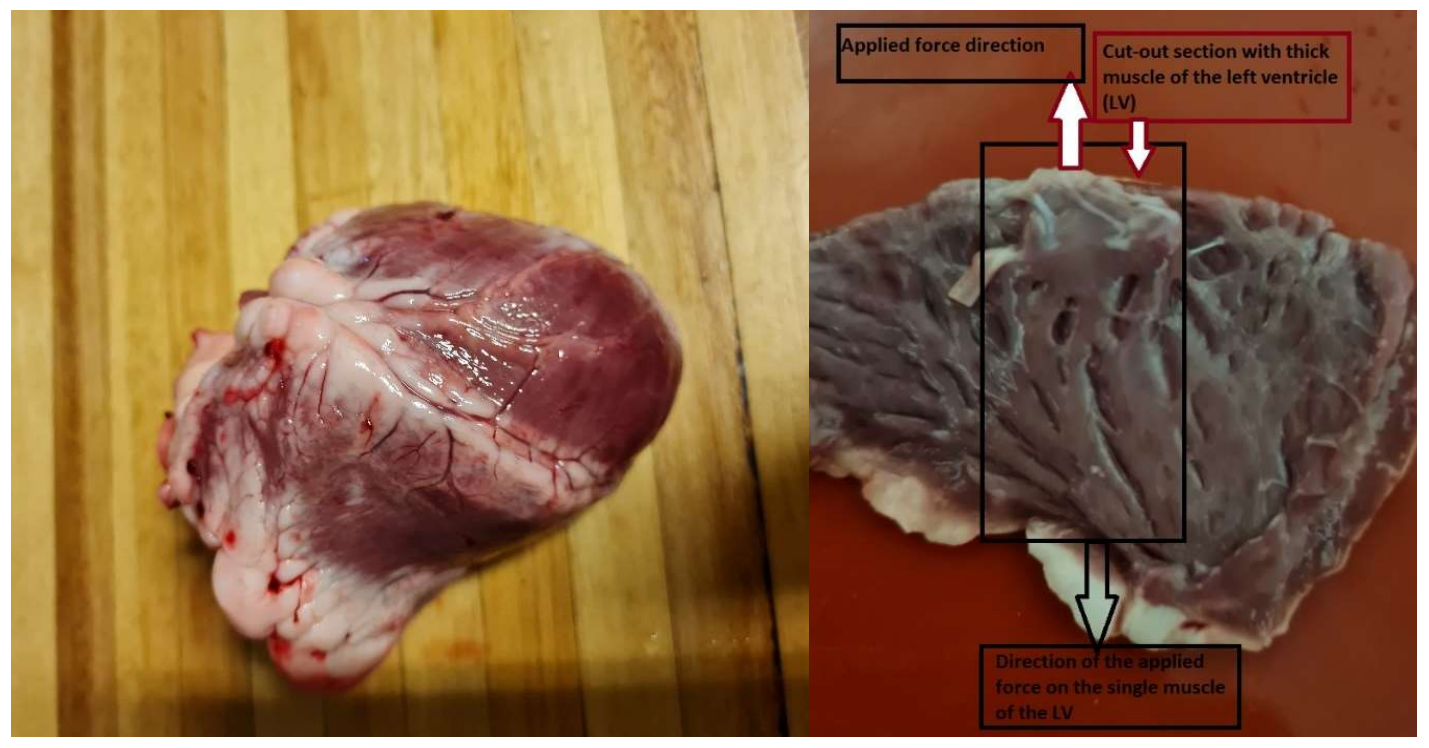

(a)

(b)

Figure 1: Fresh sheep heart collected from the local abattoir of unknown age showing (a) full fresh heart and (b) opened left ventricle (LV). The collected fresh sheep was then placed in an iced cooler box for 1 hour 20 minutes before testing.

\subsection{Uniaxial mechanical testing}

Ten $(\mathrm{N}=10)$ specimen of the left ventricle muscle was cut out from the sheep hearts from an unknown age, weight, and pre-heart disease. The sheep hearts were delivered from the local abattoir three hours after the slaughter. The delivery was done in a temperature-controlled bag at between $0{ }^{\circ} \mathrm{C}$ and $3{ }^{\circ} \mathrm{C}$. On arrival the temperature on the bag was measured to confirm and to ensure that mechanical properties were not compromised. The uniaxial testing was performed on the sheep strip of tissue from the left ventricle (LV) (See Figure 2). Immediately after the arrival of the specimens, the sheep hearts were dissected to extract the selected muscle fibre and thereafter stored in a 
$0.9 \% \mathrm{NaCl}$ physiological saline solution (PSS) for 20 minutes before mechanical testing. A total of 10 uniaxial tests were done on the LV muscle fibre. During testing there were minimal challenges like tearing of tissue, fixation movement and tissue rapturing prematurely. The dissected LV muscle fibre was then mechanically tested using CellScale UStretch (Watreloo, Canada) with a load cell of $44 \mathrm{~N}$ and force accuracy of $0.2 \%$ of the load capacity. The specimens were deposited in a bath filled with $0.9 \% \mathrm{NaCl}$ physiological saline solution. The $0.9 \% \mathrm{NaCl}$ physiological saline solution was first heated to reach a temperature of $37{ }^{\circ} \mathrm{C}$ to mimic the body temperature. Each sample was immersed for four minutes before actual testing happened. To minimise the effect of strain measurements, the needles of the BioRake were inserted at a minimum of $0.2 \mathrm{~mm}$ from the edge.

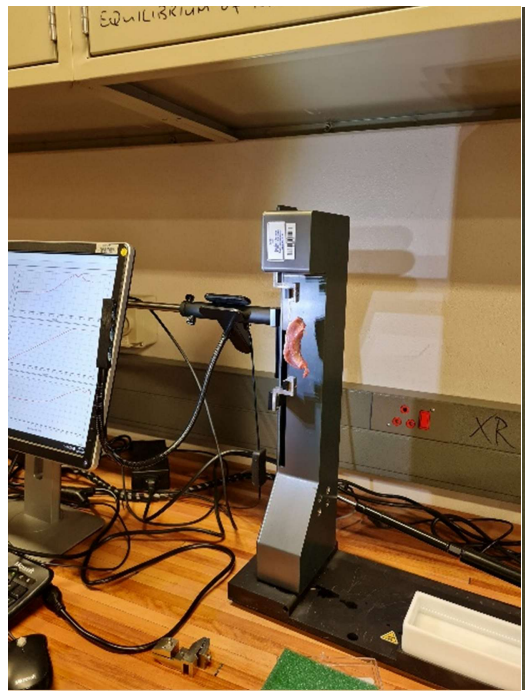

(a)

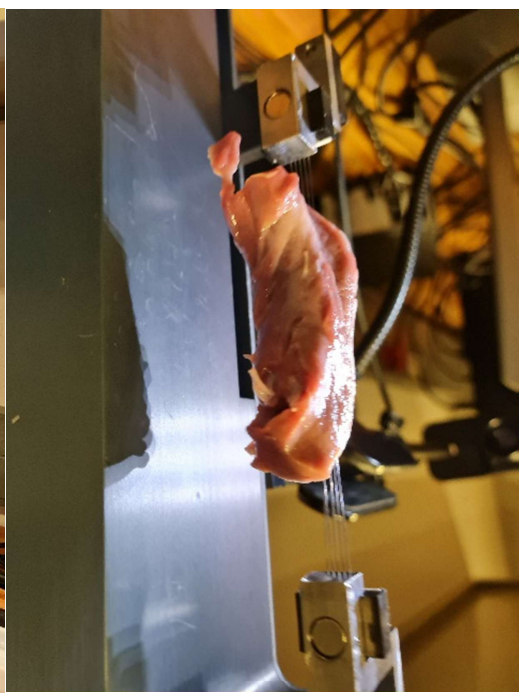

(b)

Figure 2: Experimental set-up of uniaxially tested sheep heart fibre

\subsection{Tissue stress-stretch analysis}

The engineering stress and strain is determined from the force and displacement obtained during enlongation of the muscle fibre of the sheep during unixaila testing.

$\sigma_{i}=\frac{F_{i}}{A_{i}}$

$\varepsilon_{i}=\frac{\Delta l}{l_{o}}$

(2)

$A_{i}=t \times l_{h}$

(3)

Where:

$A_{i}-$ is the cross sectional area of the sheep muscle fibre

$\Delta l-$ is the change in length

$l_{o}$ - Original length 
$\sigma_{i}-$ Engineering stress

$\varepsilon_{i}-$ Engineering strain?

$t$ - average thickness of the muscle fibre

$l_{h}$ - Breadth of the muscle fibre

\subsection{Evaluation index (EI) of the capability of anisotropic hyperelastic models}

To magnify the difference between coefficient of determination $\left(\mathrm{R}^{2}\right)$ values, the evaluation index (EI) that can assess which models are better than the others was defined [19].

Evaluation Index $(E I)=\left[\frac{r-r_{\text {minimum }}}{r_{\text {maximum }}-r_{\text {minimum }}}\right]$

$r=\operatorname{abs}\left[\log _{10}\left(1-R^{2}\right)\right]$

Where $r$ is the quantity that is based on coefficient of determination $\left(\mathrm{R}^{2}\right)$ and is expressed in Equation (5). The $r_{\text {minimum }}$ and $r_{\text {maximum }}$ values are minimum $r$ value for worst hyperelastic model and maximum $r$ value for best hyperelastic model, respectively. When EI is 100 then it means that the hyperelastic model is the best. In addition, the greater the coefficient of determination $\left(R^{2}\right)$ the greater the EI value.

\subsection{Selected hyperelastic anisotropic constitutive models}

It has been proven that like most soft biological tissues, when subjected to the mechanical force, the heart tissue exhibits strong nonlinearity, large strains and anisotropic elastic behaviour due to the presence of preferred directions in its microstructure and reorientation of the fibre directions with deformation. To develop computational models for simulation, the material parameters from hyperplastic constitutive models are required. These parameters are normally utilised to predict the mechanical response of the myocardium of the sheep. In this study, Fung, Polynomial (Anisotropic), Holzapfel (2000), Holzapfel (2005) and Four-fibre Family models were selected. The selected hyperelastic constitutive models were fitted using Hyperfit@ [20].

\subsubsection{Fung model}

The Fung model is a hyperelastic anisotropic material model proposed by Fung et al [21] for the stress-strain description of the arterial wall. The model is fully phenomenological and formulated through the components of Green-Langrange strain tensor in cylindrical polar coordinates of the artery (R-radial, - circumferential, Z-axial). Exponential stress-strain behaviour is a characteristic feature of this model:

$\psi_{(E)}=\frac{c}{2}\left(e^{Q}-1\right)$

(6)

$Q=b_{1} E_{\theta \theta}^{2}+b_{2} E_{Z Z}^{2}+b_{3} E_{R R}^{2}+2 b_{4} E_{\theta \theta} E_{Z Z}+2 b_{5} E_{Z Z} E_{R R}+2 b_{6} E_{R R} E_{\theta \theta}$

Where:

$\psi-$ is the strain energy density 
$E_{i j}$ - are components of Green-Lagrange strain tensor E referred to cylindrical polar coordinates $(R, \Theta, Z)$ in the reference configuration

$\mathrm{C}$ - is the stress-like material parameter

$b_{1}, b_{2} \ldots b_{3}$ are dimensions material parameters

\subsubsection{Polynomial (Aniso) Model}

Polynomial (Aniso) model is hyperelastic anisotropic material model defined through polynomial series of strain invariants $\left(\mathrm{I}_{\mathrm{i}}\right)$. The model definition is adopted from the ANSYS finite element package and simplified to symmetrical configuration of fibre families and to only $I_{1}, I_{2}, I_{4}\left(I_{6}\right)$ dependence. Incompressible formulation of this model is used in Hyperfit implementation.

$\psi_{\left(I_{1}, I_{2}, I_{4}, I_{6}\right)}=\sum_{i=1}^{3} a_{i}\left(I_{1}-3\right)^{i}+\sum_{j=1}^{3} b_{j}\left(I_{2}-3\right)^{j}+\sum_{k=2}^{6} c_{k}\left(I_{4}-1\right)^{k}+\sum_{m=2}^{6} e_{m}\left(I_{6}-1\right)^{m}$

$I_{4}=C: A_{0} ; \quad I_{6}=C: B_{0}$

$A_{0}=a_{0} \otimes a_{0} ; \quad B_{0}=b_{0} \otimes b_{0}$

for the specific coordinate system (corresponding to the supported data protocols) and for the symmetric configuration of fibre families:

$a_{0}=\left[\begin{array}{c}\cos \varphi \\ \sin \varphi \\ 0\end{array}\right] ; \quad b_{0}=\left[\begin{array}{c}\cos \varphi \\ -\sin \varphi \\ 0\end{array}\right]$

Where:

$\Psi$ - is strain energy density

$I_{1}, I_{2}, I_{4}, I_{6}$ - are (pseudo-) invariants of $C$ (and A0, B0)

$\mathrm{C}$ - is right Cauchy-Green def. tensor

$A_{0}, B_{0}$ - are structural tensors referenced to individual family of fibres

$a_{0}, b_{0}$ - are the direction vectors defining the orientation of fibre families

$a_{i}, b_{j}$ - are stress-like material parameters referenced to isotropic (matrix) properties

$c_{k}=\left(=e_{k}\right)$ - are stress-like material parameters referenced to anisotropic (fiber) properties

$\varphi$ - is material parameter defining the orientation angle of fibres (measured from axis " 1 ") in the undeformed configuration.

\subsubsection{Holzapfel (2000) Model}

The Holzapfel (2000) model is a hyperelastic anisotropic material model proposed by Gerhard Holzapfel et al [22] for stress-strain description of arterial layers. The model is characterised by an isotropic matrix of neoHookean form and anisotropic contribution of two symmetrical (and mechanically equivalent) families of (collagen) fibres reinforcing a vessel wall layer. Incompressible and Nearly-Incompressible (NI) formulations of this model are available in Hyperfit.

$\Psi_{\left(I_{1}, I_{4}, I_{6}\right)}=\Psi_{g\left(I_{1}\right)}+\Psi_{f\left(I_{4}, I_{6}\right)}$

$\Psi_{g\left(I_{1}\right)}=\frac{\mu}{2}\left(I_{1}-3\right)$ 
$\Psi_{g\left(I_{4}, I_{6}\right)}=\frac{k_{1}}{2 k_{2}} \sum_{i=4,6}\left(e^{k_{2}\left(I_{i}-1\right) 1^{2}}-1\right)$

Where:

$\Psi$ - is strain energy density

$I_{1}, I_{2}, I_{4}$ - are (pseudo-)invariants of $\mathrm{C}$ (and $\left.\mathrm{A}_{0}, \mathrm{~B}_{0}\right)$

is stress-like material parameter referenced to matrix properties

$\mathrm{k}_{1}$ - is stress-like material parameter referenced to fibre properties

$\mathrm{k}_{2}$ - is dimensionless material parameter referenced to fibre properties

$\varphi$ - is material parameter defining the orientation angle of fibres (measured from axis "1") in the undeformed configuration

d - is material parameter related to volumetric compressibility

\subsubsection{Holzapfel (2005) Model}

The Holzapfel (2005) model is a hyperelastic anisotropic material model proposed by Gerhard Holzapfel et al [23] for stress-strain description of arterial layers. The model represents a composite material reinforced by two families of (collagen) fibres that are mechanically equivalent and arranged in symmetrical spirals (in arterial layer). Incompressible formulation of this model is used in Hyperfit implementation.

$\Psi=\mu\left(I_{1}-3\right)+\sum_{i=1,2} \Psi_{f, i}\left(I_{1}, I_{4 i}\right)$

$\Psi_{f, i}=\frac{k_{1}}{2 k_{2}}\left(e^{k_{2}\left[(1-\rho)\left(I_{1}-3\right)^{2}+\rho\left(I_{4 i}-1\right)^{2}\right]}-1\right)$

$I_{4 i}=A_{0 i}: C$

$A_{0 i}=a_{0 i} \otimes a_{o i}$

$a_{01}=\left[\begin{array}{c}\cos \varphi \\ \sin \varphi \\ 0\end{array}\right] ; a_{02}=\left[\begin{array}{c}\cos \varphi \\ -\sin \varphi \\ 0\end{array}\right]$

$\Psi$ - is strain energy density

$\mathrm{I}_{1}, \mathrm{I}_{4}$ 1, I $\mathrm{I}_{2}$ - are (pseudo-)invariants of C

$\mathrm{C}$ - is right Cauchy-Green def. tensor

$\mathrm{A}_{01}, \mathrm{~A}_{02}$ - are structural tensors referenced to individual family of fibres

a01, $\mathrm{a}_{22}$ - are the direction vectors defining the orientation of fibre families

$\mu$ - is stress-like material parameter referenced to matrix properties

$\mathrm{k}_{1}$ - is stress-like material parameter referenced to fibre properties

$\mathrm{k}_{2}$ - is dimensionless material parameter referenced to fibre properties

$\varphi$ - is structure parameter defining the (mean) orientation angle of fibre families (measured from axis "1") in the undeformed configuration

$\rho$ - is the dimensionless parameter that can be seen as a weighting factor (from 0 to 1 : value of 0 specifies isotropic model similar to the Demiray model, value of 1 leads to Holzapfel, 2000 model) 


\subsubsection{Four-fibre Family model (FFF)}

Four-fiber Family model is a hyperelastic anisotropic material model adopted from Ferruzzi et al [24] that refers to Baek et al [25]. The model is normally utilised for stressstrain description of aortas and aneurysms. The model represents an elastin-dominated amorphous matrix reinforced by four families of (collagen) fibres (in axial, circumferential and diagonal directions). The third constitutive model, called the Four-fibre Family (FFF), is a hyperelastic anisotropic model proposed by Baek et al [25] and Ferruzzi et al [24] for the stress-strain description of aortas and aneurysms. It is a variation of the HGO model, in which two more fibre families are added in longitudinal and circumferential orientations, respectively. This model therefore presents a total of four families of fibres; one axial, one circumferential and two symmetrical in diagonal directions. Its SEF adopts the following express:

$\Psi_{\left(C_{2} A_{0 i}\right)}=\Psi_{g(C)}+\Psi_{f\left(C_{2} A_{0 i}\right)}$

$\Psi_{g(C)}=\frac{1}{2}\left(I_{1}-3\right)$

$\Psi_{f\left(C, A_{0 i}\right)}=\sum_{i=1}^{4} \frac{c_{1 i}}{4 c_{2 i}}\left\{\exp \left[c_{2 i}\left(I_{4 i}-1\right)^{2}\right]-1\right\}$

Where:

$a_{0 i}=\left[\begin{array}{l}0 \\ 1 \\ 0\end{array}\right] ; a_{02}=\left[\begin{array}{l}1 \\ 0 \\ 0\end{array}\right] ; a_{03}=\left[\begin{array}{c}\cos \varphi_{0} \\ \sin \varphi_{0} \\ 0\end{array}\right] ; a_{04}=\left[\begin{array}{c}\cos \varphi_{0} \\ -\sin \varphi_{0} \\ 0\end{array}\right]$

$\Psi$ is strain energy density

$\mathrm{I}_{1}$ is the first invariant of $\mathrm{C}$

$\mathrm{I}_{4 \mathrm{i}}$ are (pseudo-)invariants of $\mathrm{C}$ and $\mathrm{A} 0 \mathrm{i}(\mathrm{i}=1$ to 4$)$

$\mathrm{C}$ is right Cauchy-Green def. tensor

$\mathrm{A}_{01}, \mathrm{~A}_{02}$ are structural tensors referenced to individual fibre familes ( $\mathrm{i}=1$ to 4 )

a01, a02 are unit vectors defining the orientation of individual fibre families (i=1 to $4, \mathrm{i}=1$ axis 2 (axial), $\mathrm{i}=2 \sim$ axis 1 (circ.), $\mathrm{i}=3,4 \sim$ diagonal dirs.)

$\mathrm{c}$ is stress-like material parameter referenced to matrix properties

$\mathrm{Cli}_{\mathrm{i}}(\mathrm{i}=1,2,34)$ are stress-like material parameters referenced to properties of individual fibre families c2i $(\mathrm{i}=1,2,34)$ are dimensionless material parameters referenced to properties of individual fibre families

$\varphi_{0}$ is structure parameter defining the orientation angle of diagonal fibre families (measured from axis "1") in the undeformed configuration

\subsection{Numerical analysis}

This algorithm is the COBYLA method implemented as third-party library. SciPy library is adopted for this implementation. COBYLA method performs constrained 
optimisation by the linear approximation method. Coefficient of determination $\left(R^{2}\right)$ (also known as Nash-Sutcliffe coefficient)

$R^{2}=1-\frac{\sum_{i=1}^{n}\left(y_{e}-y_{m}\right)^{2}}{\sum_{i=1}^{n}\left(y_{e}-\overline{y_{e}}\right)^{2}}$

Range:

$R^{2} \epsilon\langle-\infty, 1\rangle$

For perfect fit:

$R^{2}=1$

Where:

ye is experimental (observed) value of the fitted function

$y_{m}$ is the model (theoretical) value of the fitted function

$i$ is the data point index

$\mathrm{n}$ is the number of data-points

$\mathrm{ye}_{\mathrm{e}}$ is the mean value from the experimental values calculated as follows:

$\overline{y_{e}}=\frac{1}{n} \sum_{i=1}^{n} y_{e}$

Correlation coefficient (r) is defined as follows:

$r=\frac{\sum_{i=1}^{n}\left(y_{e}-\overline{y_{e}}\right)\left(y_{m}-\overline{y_{m}}\right)}{\sqrt{\sum_{i=1}^{n}\left(y_{m}-\overline{y_{m}}\right)^{2}} \cdot \sum_{i=1}^{n}\left(y_{m}-\overline{y_{m}}\right)^{2}}$

Where:

$\overline{y_{m}}$ is the mean value from the models values (calculated below):

$\overline{y_{m}}=\frac{1}{n} \sum_{i=1}^{n} y_{m}$

Normalized RMS error (NRMSE) is defined as follows:

$N R M S E=\frac{\sqrt{\frac{1}{n}} \sum_{i=1}^{n}\left(y_{e}-y_{m}\right)^{2}}{a b s\left(\overline{y_{e}}\right)}$

Normalised error (NE) is defined as follows:

$N E=\frac{\frac{1}{n} \sum_{i=1}^{n} a b s\left(y_{e}-y_{m}\right)}{a b s\left(\overline{y_{e}}\right)}$

\section{Results}

In these experiments, ten $(\mathrm{N}=10)$ specimens were extracted from ten sheep hearts and there was no visible tissue damage to all the specimens. The average measurements of the specimens were $7.45 \pm 0.43 \mathrm{~mm}$ and $15.27 \pm 0.62 \mathrm{~mm}$ for both thickness and width, respectively (See Table 1). The stress vales were calculated from the average crosssectional Area $\left(t_{i} \times w_{i}\right)$ from the average $t_{i}$ and $w_{i}$ shown in Table 1.

Table 1: Measurements of thickness and width of the dissected fibre from the LV

\begin{tabular}{|l|r|r|}
\hline & Thickness $(\mathrm{t})(\mathrm{mm})$ & Width $(\mathrm{w})(\mathrm{mm})$ \\
\hline Specimen 1 & 7.65 & 15.36 \\
\hline
\end{tabular}




\begin{tabular}{|l|r|r|} 
Specimen 2 & 7.33 & 13.85 \\
\hline Specimen 3 & 6.87 & 14.95 \\
\hline Specimen 4 & 7.63 & 15.70 \\
\hline Specimen 5 & 8.20 & 15.22 \\
\hline Specimen 6 & 7.95 & 15.28 \\
\hline Specimen 7 & 7.55 & 16.35 \\
\hline Specimen 8 & 6.58 & 14.80 \\
\hline Specimen 9 & 7.38 & 15.95 \\
\hline Specimen 10 & 7.42 & 15.20 \\
\hline Average & 7.46 & 15.27 \\
\hline STD & 0.43 & 0.62 \\
\hline
\end{tabular}

\subsection{Uniaxial mechanical response}

All ten (10) specimens were subjected to uniaxial forces at the same strain rate. The average stress at 0.5 strain for all ten specimens were found to be $31.44 \pm 12.32 \mathrm{kPa}$. The maximum stress at 0.5 strain was found to be $48.49 \mathrm{kPa}$. Ten $(\mathrm{N}=10)$ specimens were subjected to uniaxial testing at the same strain rate. All the thickness and width of the sample were measured before testing to ensure that the cross-sectional area of the specimen can be calculated. The average thickness and width of all specimens were calculated to be $7.76 \mathrm{~mm} \pm 0.43 \mathrm{~mm}$ and $15.27 \mathrm{~mm} \pm 0.62 \mathrm{~mm}$, respectively (See Table 1). Figure 3 shows the stress vs strain of the ten specimens of the sheep fibre of the LV. The mechanical response of the sheep fibre of the LV exhibits the hyperelatic and non-linear material behaviour (See Figure 3). However, it was observed that specimen 3 exhibited the lowest engineering stress when compared to the rest of the specimens that were tested. In addition, the stress at 50\% strain was captured and the average stress at $50 \%$ was calculated to be $33.4 \mathrm{kPa}$ (see Figure 4). The maximum and minimum stress at $50 \%$ strain was captured to be $48.49 \mathrm{kPa}$ and $4.98 \mathrm{kPa}$, respectively as shown in Figure 4 . The standard deviation (STDEV) was calculated to be $12.32 \mathrm{kPa}$. Figure 5 shows the typical fitting of experimental data using the hyperelastic Fung model. 


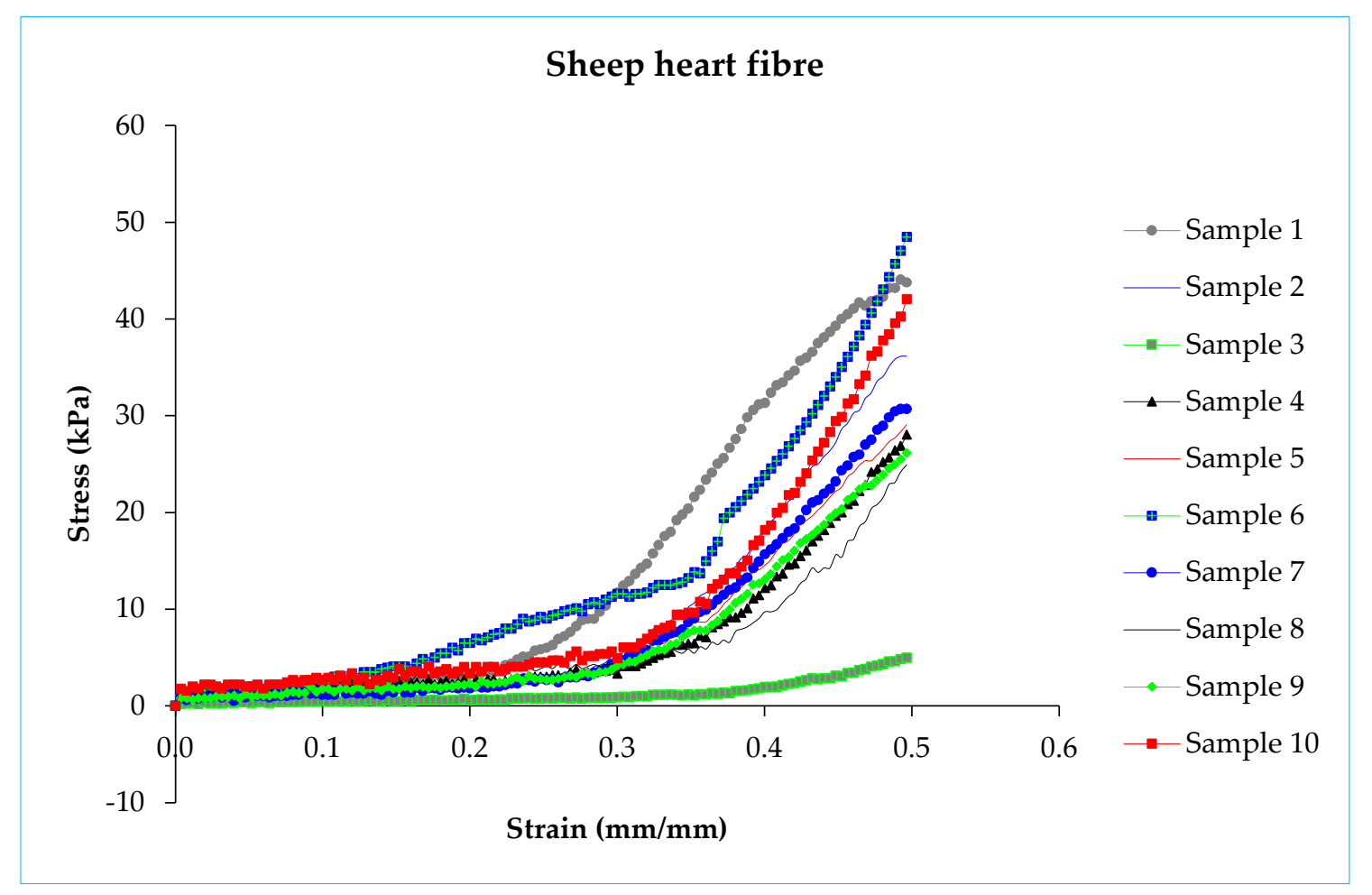

Figure 3: Uniaxial strain-stress for the fibre on the LV of the sheep myocardium

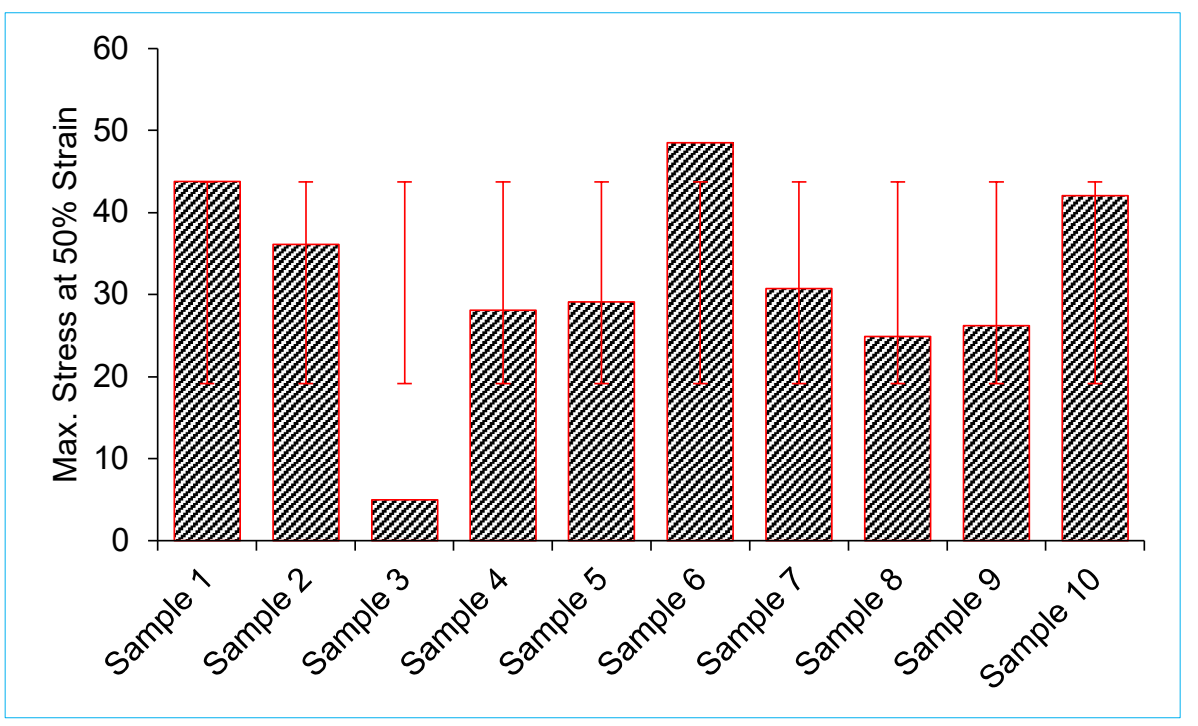

Figure 4: Maximum stress at 50\%

Five hyperelastic models were selected to fit the experimental data of the sheep fibre dissected from the LV. These hyperplastic models are Fung, Four-fibre Family, Polynomial (Anisotropic), Holzapfel (2000) and Holzapfel (2005). The fitting was done using HyperFit ${ }^{\circledR}$ software utiling COBYLA ( $3^{\text {rd }}$ party: SciPy) optimisation methods. Coefficient of Determination (Fit) (R2), Correlation coefficient (r), Normalised Error (NE) 
and Normalised RMS Error (NRMSE) were captured in order to compare the fitability of the experimental data with all the selected hyperelastic models. All material parameters calculated from the strain energy function of each hyperelastic models are presented in Tables 2, 3, 4, 5 and 6. Table 1 shows that the average coefficient of determination $\left(R^{2}\right)$ for all ten samples was 0.98 . The average coefficient of determination $\left(R^{2}\right)$ for Fung, Four-fibre Family, Polynomial (Anisotropic), Holzapfel (2000) and Holzapfel (2005) were found to be $0.98,0.98,0.99,0.96$ and 0.97, respectively. Also, as shown in Tables 2, 3, 4, 5 and 6, the average correlation coefficient (r) for Fung, Polynomial (Anisotropic), Four-fibre Family, Holzapfel (2000) and Holzapfel (2005) hyperelastic models was calculated to be 0.99, 0.99, $0.99,0.98$ and 0.99 , respectively. In addition, $0.15,0.13,0.2,0.17,0.16$ was found to be the average normalised RMS Error (NRMSE) of the experimental data fitted on Fung, Polynomial (Anisotropic), Holzapfel (2000), Holzapfel (2005)and Four-fibre Family hyperelastic models, respectively. Lastly, the average Normalised Error (NE) was determined to be $0.13,0.10,0.16,0.14$ and 0.13 , respectively for Fung, Polynomial (Anisotropic), Holzapfel (2000), Holzapfel (2005) and Four-fibre Family hyperelastic models (See Tables 2, 3, 4, 5 and 6). In determining how best the experiment data curve fitted into the selected hyperelastic models, the average correlation coefficient ( $\mathrm{r}$ ) of all specimens was calculated to be 0.99, 0.99, 0.98, 0.99 and 0.99 for Fung, Polynomial (Anisotropic), Holzapfel (2000), Holzapfel (2005)and Four-fibre Family hyperelastic models, respectively.

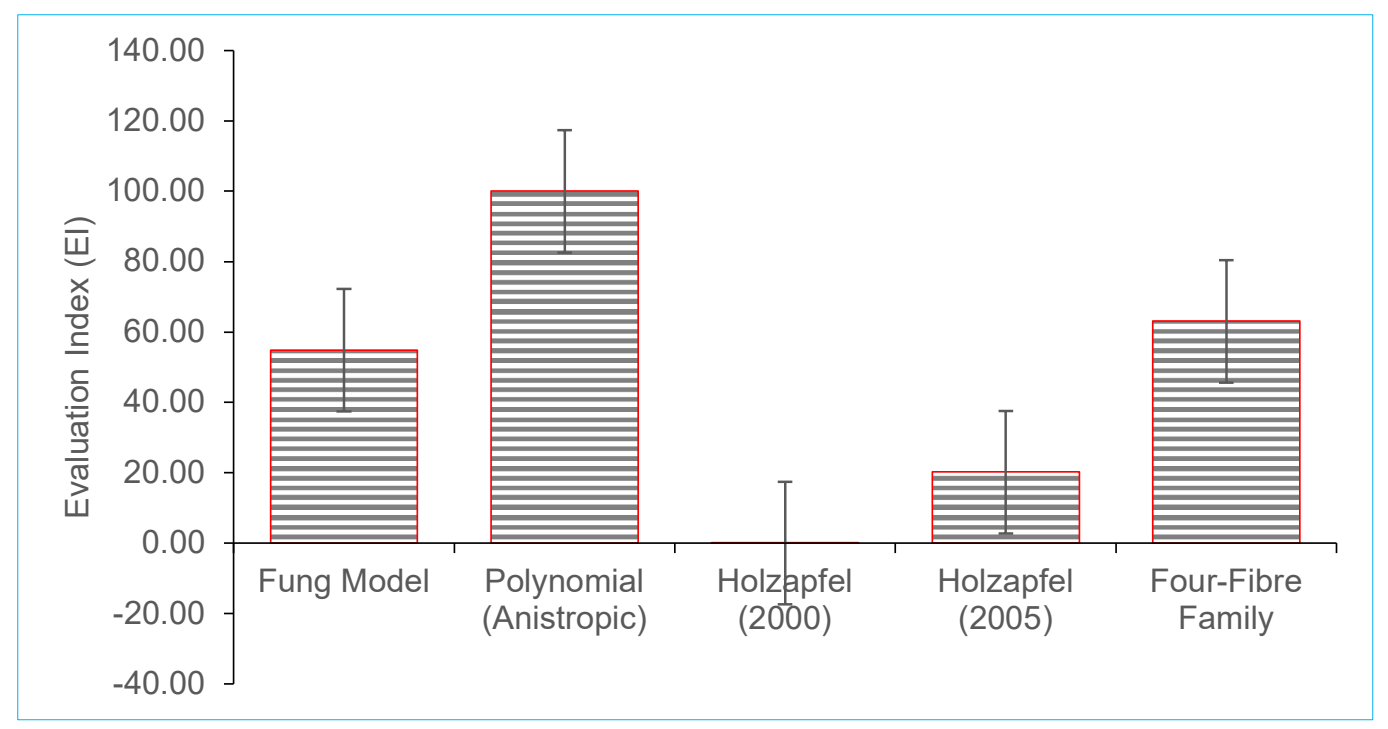

Figure 5: Evaluation Index calculated for Fung, Polynomial (anisotropic), Holzapfel (2000), Holzapfel (2005) and FourFibre Family hyperelastic models for average (based on $N=10$ samples) coefficient of determination $\left(R^{2}\right)$ based on Equation (4).

Figure 5 shows that the Polynomial (Anisotropic) model has the EI of 100 and this means that it is the best performance when compared to all the others. Four-fibre Family model has the EI of 63 and therefore regarded as number 2 in terms of performances when 
fitted on the uniaxial experimental data of the sheep heart fibre. The worst performer with EI of 0 is the Holzapfel (2000) model.

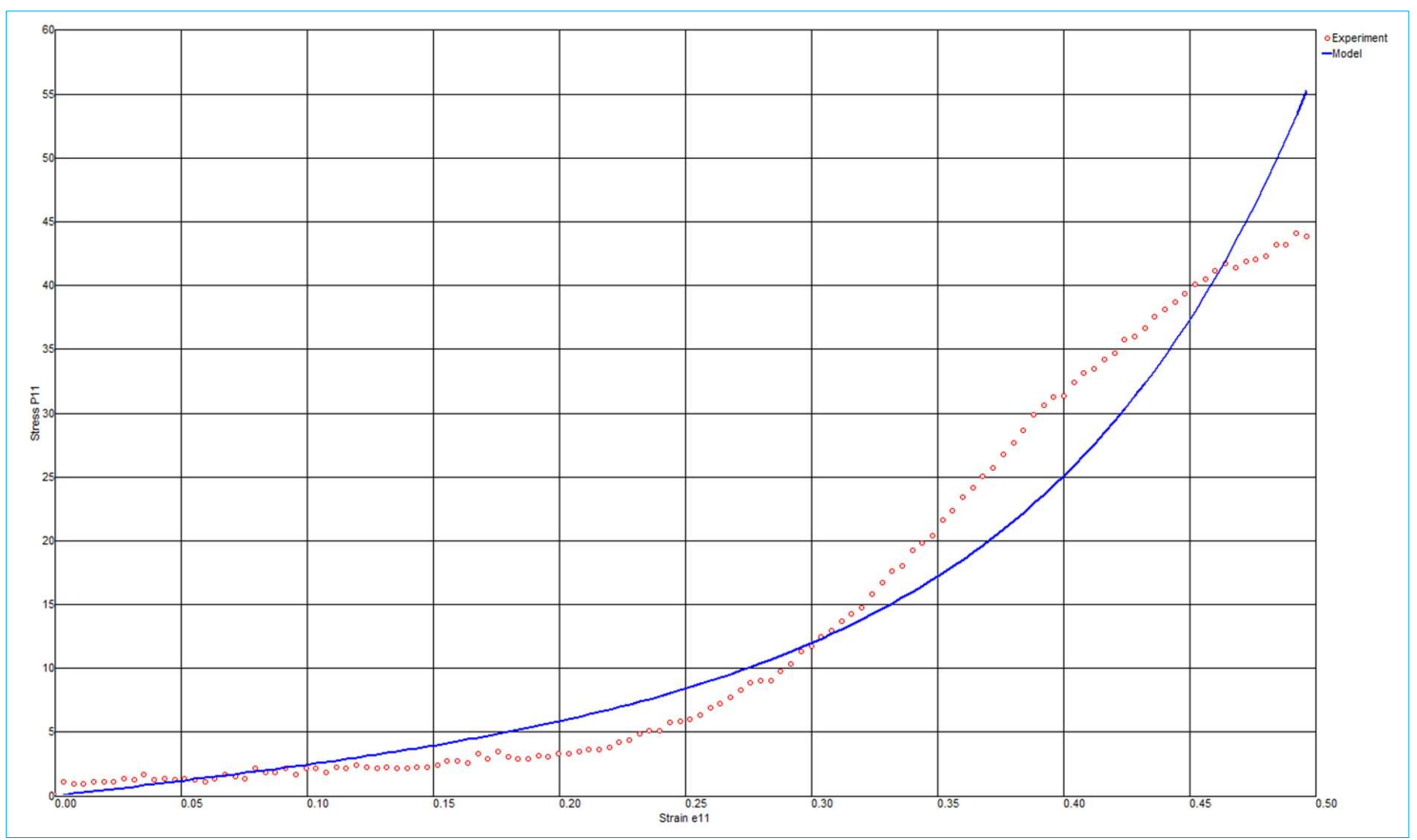

Figure 6: Example of consitutive hyperelastic model Fitting of Fung model processed for Sample 1

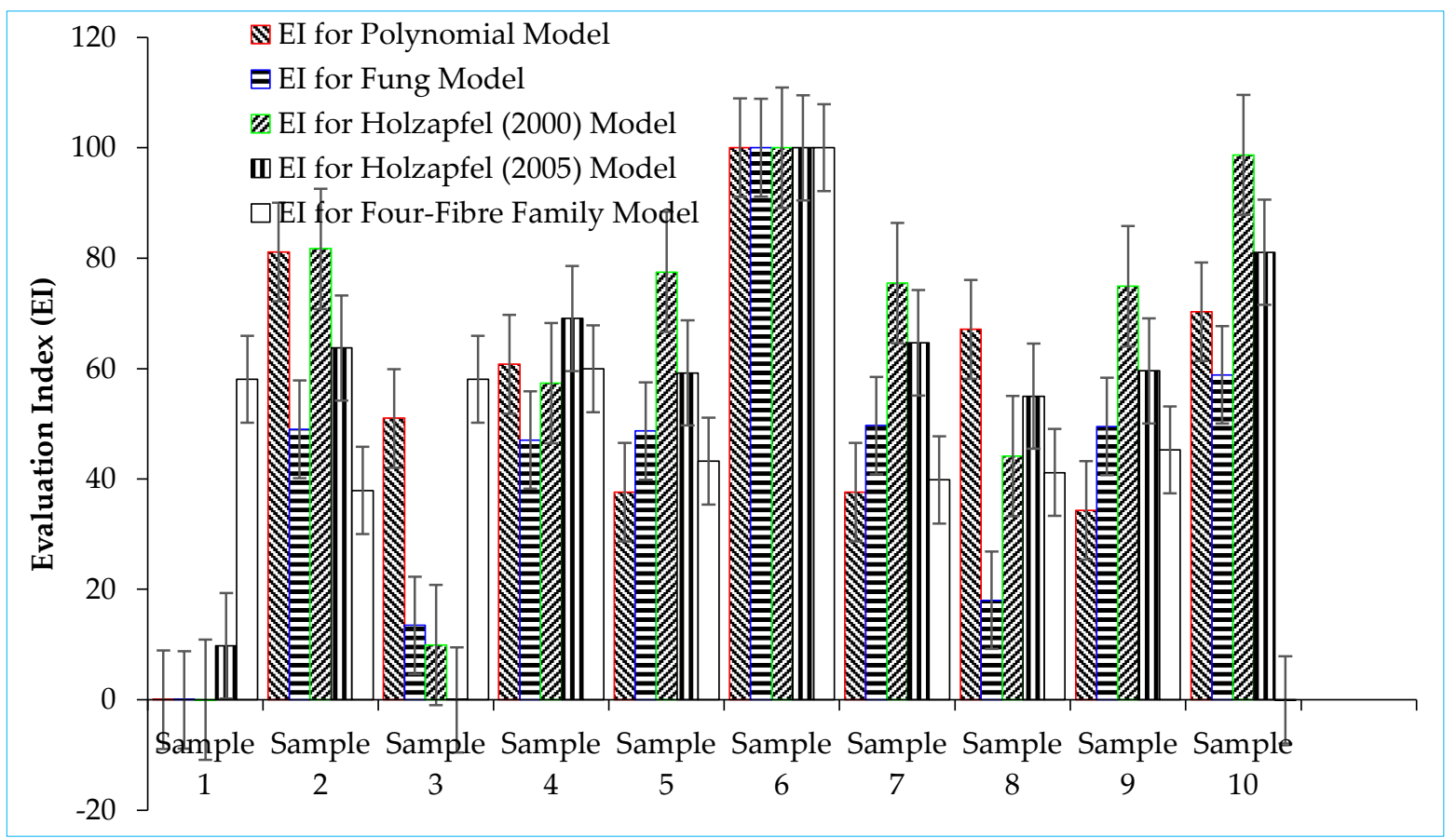

Figure 7: Evaluation Index (EI) with standard error calculated per sample for Fung, Polynomial (Anisotropic), Holzapfel (2000), Holzapfel (2005) and Four-fibre Family hyperelastic models. 
Table 1: Fung Model material parameters (c, $\left.b_{i}\right)$ calculated from Equation 3, coefficient of determination $\left(R^{2}\right)$ and the average values of $\left(c, b_{i}\right.$ and $\left.R^{2}\right)$ for the dissected sheep heart muscle.

\begin{tabular}{|c|c|c|c|c|c|c|c|c|c|c|c|}
\hline & $\begin{array}{l}\text { Sample } \\
01\end{array}$ & $\begin{array}{l}\text { Sample } \\
02\end{array}$ & $\begin{array}{l}\text { Sample } \\
03\end{array}$ & $\begin{array}{l}\text { Sample } \\
04\end{array}$ & $\begin{array}{l}\text { Sample } \\
05\end{array}$ & $\begin{array}{l}\text { Sample } \\
06\end{array}$ & $\begin{array}{l}\text { Sample } \\
07\end{array}$ & $\begin{array}{l}\text { Sample } \\
08\end{array}$ & $\begin{array}{l}\text { Sample } \\
09\end{array}$ & $\begin{array}{l}\text { Sample } \\
10\end{array}$ & Average \\
\hline Coefficient of & & & & & & & & & & & \\
\hline Determination (Fit) $\left(\mathrm{R}^{2}\right)$ & 0.955 & 0.983 & 0.964 & 0.985 & 0.982 & 0.994 & 0.983 & 0.968 & 0.983 & 0.986 & 0.978 \\
\hline Correlation coefficient ( $r$ ) & 0.978 & 0.991 & 0.984 & 0.993 & 0.991 & 0.997 & 0.992 & 0.989 & 0.991 & 0.993 & 0.990 \\
\hline Normalised Error (NE) & 0.180 & 0.120 & 0.156 & 0.118 & 0.119 & 0.062 & 0.123 & 0.149 & 0.120 & 0.116 & 0.126 \\
\hline Norm. RMS Error (NRMSE) & 0.223 & 0.154 & 0.176 & 0.133 & 0.145 & 0.076 & 0.154 & 0.169 & 0.144 & 0.130 & 0.150 \\
\hline c & 4.930 & 2.084 & 0.426 & 1.375 & 1.909 & 4.389 & 1.817 & 1.558 & 1.659 & 1.844 & 2.199 \\
\hline b1 & 1.483 & 3.536 & 2.495 & 2.895 & 3.132 & 2.364 & 3.281 & 2.441 & 2.628 & 2.957 & 2.721 \\
\hline b2 & 0.737 & 0.676 & -0.030 & -0.047 & 0.352 & -0.335 & 0.196 & -0.133 & 0.038 & 0.406 & 0.186 \\
\hline b3 & -0.866 & -1.337 & -0.577 & -1.614 & -1.437 & -0.130 & -1.118 & -1.565 & -1.620 & -0.719 & -1.098 \\
\hline b4 & -1.006 & -0.028 & -0.878 & -0.599 & -0.546 & -0.129 & -0.564 & -0.731 & -0.503 & -0.330 & -0.531 \\
\hline b5 & 2.370 & 1.070 & 1.087 & 0.352 & 0.814 & 2.877 & 1.339 & 0.629 & 0.287 & 2.489 & 1.331 \\
\hline b6 & -2.129 & -1.010 & -0.560 & -2.142 & -1.125 & -1.125 & -1.045 & -1.994 & -2.071 & -2.030 & -1.523 \\
\hline
\end{tabular}

Table 2: Polynomial (Anisotropic) material parameters $\left(\mathrm{a}_{i}, b_{i}, c_{i}, \varphi, N R M S E, N E, r\right.$ and $\left.R^{2}\right)$ calculated from Equation (5), coefficient of determination $\left(R^{2}\right)$ and the average values of $\left(a_{i}, b_{i}, c_{i}, \varphi, N R M S E, N E, r\right.$ and $\left.R^{2}\right)$ for the dissected sheep heart muscle.

\begin{tabular}{|c|c|c|c|c|c|c|c|c|c|c|c|}
\hline & $\begin{array}{l}\text { Sample } \\
01\end{array}$ & $\begin{array}{l}\text { Sample } \\
02\end{array}$ & Sample 03 & $\begin{array}{l}\text { Sample } \\
04\end{array}$ & $\begin{array}{l}\text { Sample } \\
05\end{array}$ & $\begin{array}{l}\text { Sample } \\
06\end{array}$ & $\begin{array}{l}\text { Sample } \\
07\end{array}$ & $\begin{array}{l}\text { Sample } \\
08\end{array}$ & $\begin{array}{l}\text { Sample } \\
09\end{array}$ & Sample 10 & Average \\
\hline $\begin{array}{l}\text { Coefficient of } \\
\text { determination } \\
\left(R^{2}\right)\end{array}$ & 0.976 & 0.990 & 0.986 & 0.987 & 0.984 & 0.991 & 0.984 & 0.988 & 0.983 & 0.988 & 0.986 \\
\hline $\begin{array}{l}\text { Norm. RMS } \\
\text { Error (NRMSE) }\end{array}$ & 0.161 & 0.120 & 0.111 & 0.122 & 0.139 & 0.089 & 0.150 & 0.103 & 0.142 & 0.117 & 0.126 \\
\hline $\begin{array}{l}\text { Correlation } \\
\text { coefficient (r) }\end{array}$ & 0.989 & 0.995 & 0.993 & 0.994 & 0.992 & 0.997 & 0.992 & 0.996 & 0.992 & 0.996 & 0.993 \\
\hline $\begin{array}{l}\text { Normalised } \\
\text { Error (NE) }\end{array}$ & 0.133 & 0.095 & 0.093 & 0.102 & 0.113 & 0.073 & 0.119 & 0.083 & 0.113 & 0.104 & 0.103 \\
\hline a1 & 0.769 & 1.081 & 0.851 & 0.851 & 1.045 & 0.817 & 1.101 & 0.848 & 0.932 & 1.277 & 0.957 \\
\hline $\mathrm{a}_{2}$ & 1.029 & 1.361 & -0.124 & 0.948 & 1.025 & 0.875 & 1.191 & 0.801 & 0.998 & 0.979 & 0.908 \\
\hline a3 & 1.044 & 1.442 & 1.159 & 1.258 & 1.283 & 0.838 & 1.241 & 1.079 & 1.153 & 0.979 & 1.148 \\
\hline$b_{1}$ & 0.016 & -0.003 & 0.870 & 0.010 & -0.166 & 0.022 & -0.117 & 0.088 & -0.053 & -0.015 & 0.065 \\
\hline$b_{2}$ & -0.047 & 0.031 & 0.007 & 0.008 & 0.044 & 0.008 & -0.139 & -0.074 & 0.019 & -0.173 & -0.032 \\
\hline$b_{3}$ & 0.029 & 0.495 & 0.045 & 0.002 & 0.280 & -0.016 & -0.098 & -0.026 & 0.003 & -0.037 & 0.068 \\
\hline $\mathrm{C} 2$ & 0.701 & 0.205 & -0.027 & 0.677 & 0.523 & 0.490 & 0.482 & 0.693 & 0.580 & 0.278 & 0.460 \\
\hline $\mathrm{C}_{3}$ & 1.084 & 0.009 & -0.007 & -0.378 & -0.214 & 0.931 & -0.355 & -0.310 & -0.358 & -0.094 & 0.031 \\
\hline
\end{tabular}




\begin{tabular}{|l|l|l|l|l|l|l|l|l|l|l|l|}
\hline C4 & 0.268 & 0.140 & -0.017 & -0.075 & 0.080 & -0.268 & 0.152 & -0.130 & -0.080 & -0.340 & -0.027 \\
\hline C5 & 0.320 & 0.187 & -0.045 & 0.053 & 0.125 & 0.095 & 0.105 & -0.057 & 0.334 & 0.555 & 0.167 \\
\hline C6 & -0.185 & 0.091 & 0.057 & 0.325 & 0.240 & 0.181 & 0.163 & 0.312 & 0.054 & -0.240 & 0.100 \\
\hline phi & 0.267 & -0.051 & 0.159 & -0.221 & 0.261 & 0.126 & 0.086 & -0.173 & 0.109 & 0.028 & 0.059 \\
\hline
\end{tabular}

Comparison of how experimental data fits into the selected hyperelastic models is shown in Figures 6, 7, 8 and 9. Figure 4 shows that the best hyperelatsic model fit on the sheep heart fibre is the polylomial (anisotropric). However, the worse hyperelastic model identified was Holzapfel (2000). The Four-fibre Family hyperelastic model was seen to be the second best when fitted in the sheep fibre mechanical uniaxial test data. In addition, Figure 6 shows that the hyerelastic Fung model is third when compared to other models that were considered in this study. As expected, the least performing model, Holzapfel (2000) was recorded to have the highest normalised RMS error in most of the ten samples (See Figure 7). In comparing the hyperelastic Holzapfel (2005) and Polynomial (Anisotropic) models, the polynomial (Anisotropic) model was seen to have the lowest normalised RMS error in most of the ten samples (See Figure 7). This trend is like what has been observed in looking at the normalised error of all hyperelastic models (See Figure 8). Figure 9 shows that the hyperelastic Polynomial (Anisotropic) model has the highest correlation error when compared to others. The box plot shown in Figure 10 shows that the hyperelastic Holzapfel (2000) has the largest range of the coefficient of determination $\left(R^{2}\right)$ when compared to other four hyperelastic models. However, it is to be noted that the lowest range of the coefficient of determination (R2) is seen on the hyperelastic Fung model followed by the Polynomial (Anisotropic) model (See Figure 9). In Figure 11, the hyperelastic Holzapfel (2005) has the widest range of the normalised error (NE) when compared to other models whereas the hyperelastic Polynomial (Anisotropic) model seems to have the lowest range of normalised error as shown in Figure 11. It was observed that the widest correlation coefficient range ( $r$ ) is under the hyperelastic Holzapfel (2000) model while the Fung model has the closet range of the correlation coefficient (r).

Table 3: Holzapfel (2000) Model material parameters ( $\mu, k_{i}, \varphi, N E, N R M S E, r$ and $\left.R^{2}\right)$ calculated from Equation (9), coefficient of determination $\left(R^{2}\right)$ and the average values of $\left(\mu, k_{i}, \varphi, N E, N R M S E, r\right.$ and $\left.R^{2}\right)$ for the dissected sheep heart muscle.

\begin{tabular}{|l|l|l|l|l|l|l|l|l|l|l|l|}
\hline & $\begin{array}{l}\text { Sample } \\
01\end{array}$ & $\begin{array}{l}\text { Sample } \\
02\end{array}$ & $\begin{array}{l}\text { Sample } \\
03\end{array}$ & $\begin{array}{l}\text { Sample } \\
04\end{array}$ & $\begin{array}{l}\text { Sample } \\
05\end{array}$ & $\begin{array}{l}\text { Sample } \\
06\end{array}$ & $\begin{array}{l}\text { Sample } \\
07\end{array}$ & $\begin{array}{l}\text { Sample } \\
08\end{array}$ & $\begin{array}{l}\text { Sample } \\
09\end{array}$ & $\begin{array}{l}\text { Sample } \\
10\end{array}$ & $\begin{array}{l}\text { Average } \\
\text { Coefficient of } \\
\text { determination } \\
\left(R^{2}\right)\end{array}$ \\
\hline $\begin{array}{l}\text { Normalised } \\
\text { Error (NE) }\end{array}$ & 0.906 & 0.977 & 0.921 & 0.965 & 0.975 & 0.983 & 0.975 & 0.956 & 0.974 & 0.983 & 0.962 \\
\hline $\begin{array}{l}\text { Norm. RMS Error } \\
\text { (NRMSE) }\end{array}$ & 0.322 & 0.178 & 0.263 & 0.201 & 0.171 & 0.124 & 0.188 & 0.195 & 0.175 & 0.142 & 0.196 \\
\hline
\end{tabular}




\begin{tabular}{|l|l|l|l|l|l|l|l|l|l|l|l|}
\hline $\begin{array}{l}\text { Correlation } \\
\text { coefficient }(\mathrm{r})\end{array}$ & 0.956 & 0.990 & 0.961 & 0.984 & 0.989 & 0.996 & 0.990 & 0.978 & 0.989 & 0.991 & 0.982 \\
\hline$\mu$ & 2.114 & 2.119 & 0.453 & 2.124 & 2.180 & 2.336 & 1.881 & 2.112 & 1.882 & 2.078 & 1.928 \\
\hline $\mathrm{k}_{1}$ & 2.090 & 2.078 & 1.153 & 2.084 & 2.041 & 2.054 & 2.148 & 2.086 & 2.165 & 2.068 & 1.997 \\
\hline $\mathrm{k}_{2}$ & 1.846 & 2.021 & 2.196 & 2.043 & 2.052 & 1.574 & 2.156 & 2.031 & 2.183 & 2.013 & 2.012 \\
\hline$\varphi$ & 0.387 & 0.460 & 0.662 & 0.514 & 0.496 & 0.367 & 0.493 & 0.539 & 0.522 & 0.447 & 0.489 \\
\hline
\end{tabular}

Table 4: Holzapfel (2005) Model material parameters $\left(\mu, k_{i}, \varphi, \rho, N E, N R M S E, r\right.$ and $\left.R^{2}\right)$ calculated from Equation 12), coefficient of determination $\left(R^{2}\right)$ and the average values of $\left(\mu, k_{i}, \varphi, \rho, N E, N R M S E, r\right.$ and $\left.R^{2}\right)$ for the dissected sheep heart muscle.

\begin{tabular}{|l|l|l|l|l|l|l|l|l|l|l|l|}
\hline & $\begin{array}{l}\text { Sample } \\
01\end{array}$ & $\begin{array}{l}\text { Sample } \\
02\end{array}$ & $\begin{array}{l}\text { Sample } \\
03\end{array}$ & $\begin{array}{l}\text { Sample } \\
04\end{array}$ & $\begin{array}{l}\text { Sample } \\
05\end{array}$ & $\begin{array}{l}\text { Sample } \\
06\end{array}$ & $\begin{array}{l}\text { Sample } \\
07\end{array}$ & $\begin{array}{l}\text { Sample } \\
08\end{array}$ & $\begin{array}{l}\text { Sample } \\
09\end{array}$ & $\begin{array}{l}\text { Sample } \\
10\end{array}$ & $\begin{array}{l}\text { Averag } \\
\mathrm{e}\end{array}$ \\
\hline $\begin{array}{l}\text { Coefficient of } \\
\text { determination }\left(R^{2}\right)\end{array}$ & 0.954 & 0.963 & 0.897 & 0.982 & 0.994 & 0.994 & 0.978 & 0.973 & 0.975 & 0.984 & 0.969 \\
\hline $\begin{array}{l}\text { Normalised Error } \\
(\text { NE) }\end{array}$ & 0.183 & 0.187 & 0.268 & 0.127 & 0.063 & 0.063 & 0.139 & 0.134 & 0.142 & 0.117 \\
\hline $\begin{array}{l}\text { Norm. RMS Error } \\
\text { (NRMSE) }\end{array}$ & 0.225 & 0.226 & 0.300 & 0.145 & 0.076 & 0.076 & 0.176 & 0.154 & 0.172 & 0.139 & 0.169 \\
\hline $\begin{array}{l}\text { Correlation } \\
\text { coefficient }(\mathrm{r})\end{array}$ & 0.978 & 0.987 & 0.957 & 0.991 & 0.997 & 0.997 & 0.989 & 0.988 & 0.993 & 0.988 & 0.987 \\
\hline$\mu$ & 1.205 & 2.874 & -0.001 & 0.757 & 1.236 & 4.946 & 1.042 & 1.531 & 1.780 & 0.947 & 1.632 \\
\hline $\mathrm{k}_{1}$ & 2.447 & 3.793 & 1.743 & 1.823 & 2.037 & 5.112 & 2.342 & 2.507 & 3.132 & 2.317 & 2.725 \\
\hline $\mathrm{k} 2$ & 0.765 & 2.487 & 0.002 & 1.689 & 0.908 & 3.667 & 2.288 & 2.356 & 2.559 & 2.145 & 1.887 \\
\hline$\varphi$ & -0.188 & -0.157 & -0.005 & 0.184 & -0.103 & 1.399 & 0.400 & 0.340 & 0.311 & 0.357 & 0.254 \\
\hline$\rho$ & 1.037 & 0.107 & -0.002 & 0.403 & 0.893 & -0.010 & 0.429 & 0.152 & 0.100 & 0.528 & 0.364 \\
\hline
\end{tabular}

Table 5: Four-fibre Family model material parameters $\left(c, c_{i i}, c_{i i i}, \mu, k_{i}, \varphi_{0}, N E, N R M S E, r\right.$ and $\left.R^{2}\right)$ calculated from Equation (17), coefficient of determination $\left(R^{2}\right)$ and the average values of $\left(c, c_{i i}, c_{i i i} \mu, k_{i}, \varphi_{0}, N E, N R M S E, r\right.$ and $\left.R^{2}\right)$ for the dissected sheep heart muscle.

\begin{tabular}{|l|l|l|l|l|l|l|l|l|l|l|l|}
\hline & $\begin{array}{l}\text { Sample } \\
01\end{array}$ & $\begin{array}{l}\text { Sample } \\
02\end{array}$ & $\begin{array}{l}\text { Sample } \\
03\end{array}$ & $\begin{array}{l}\text { Sample } \\
04\end{array}$ & $\begin{array}{l}\text { Sample } \\
05\end{array}$ & $\begin{array}{l}\text { Sample } \\
06\end{array}$ & $\begin{array}{l}\text { Sample } \\
07\end{array}$ & $\begin{array}{l}\text { Sample } \\
08\end{array}$ & $\begin{array}{l}\text { Sample } \\
09\end{array}$ & $\begin{array}{l}\text { Sample } \\
10\end{array}$ & \begin{tabular}{l} 
Average \\
\hline $\begin{array}{l}\text { Coefficient of } \\
\text { determination } \\
\left(R^{2}\right)\end{array}$
\end{tabular} \\
\hline $\begin{array}{l}\text { Normalised } \\
\text { Error (NE) }\end{array}$ & 0.954 & 0.978 & 0.982 & 0.982 & 0.979 & 0.988 & 0.978 & 0.979 & 0.979 & 0.967 & 0.977 \\
\hline $\begin{array}{l}\text { Norm. RMS Error } \\
\text { (NRMSE) }\end{array}$ & 0.223 & 0.175 & 0.126 & 0.144 & 0.159 & 0.104 & 0.174 & 0.137 & 0.157 & 0.197 & 0.160 \\
\hline $\begin{array}{l}\text { Correlation } \\
\text { coefficient (r) }\end{array}$ & 0.979 & 0.990 & 0.993 & 0.991 & 0.989 & 0.996 & 0.990 & 0.994 & 0.990 & 0.986 & 0.990 \\
\hline
\end{tabular}




\begin{tabular}{|l|l|l|l|l|l|l|l|l|l|l|l|}
\hline $\mathrm{c}$ & 2.319 & 2.136 & 0.682 & 1.529 & 1.966 & 3.732 & 1.819 & 2.468 & 1.363 & 2.740 & 2.075 \\
\hline $\mathrm{C} 11$ & 0.737 & 0.695 & 0.784 & 1.001 & 0.646 & 1.118 & 0.979 & 964.000 & 1.143 & 0.767 & 97.187 \\
\hline $\mathrm{C} 21$ & 0.691 & 1.400 & 1.675 & 0.693 & 1.166 & 0.692 & 1.062 & 1.100 & 0.701 & 0.060 & 0.924 \\
\hline $\mathrm{C} 12$ & 2.123 & 2.287 & 0.210 & 1.032 & 3.146 & 5.144 & 3.033 & 1.789 & 1.198 & 3.610 & 2.357 \\
\hline $\mathrm{C} 22$ & 0.683 & 1.262 & 1.362 & 1.274 & 1.081 & 1.056 & 1.159 & 1.250 & 1.268 & 0.327 & 1.072 \\
\hline $\mathrm{C} 134$ & 3.826 & 2.422 & 1.037 & 2.203 & 2.352 & 1.022 & 2.293 & 2.094 & 2.135 & 1.936 & 2.132 \\
\hline $\mathrm{C} 234$ & 0.655 & 2.314 & 0.967 & 2.036 & 2.261 & 1.044 & 1.944 & 2.179 & 2.027 & 2.226 & 1.765 \\
\hline$\varphi_{0}$ & 0.000 & 0.583 & 1.685 & 0.509 & 1.101 & 1.771 & 0.928 & 0.972 & 0.518 & 0.432 & 0.850 \\
\hline
\end{tabular}

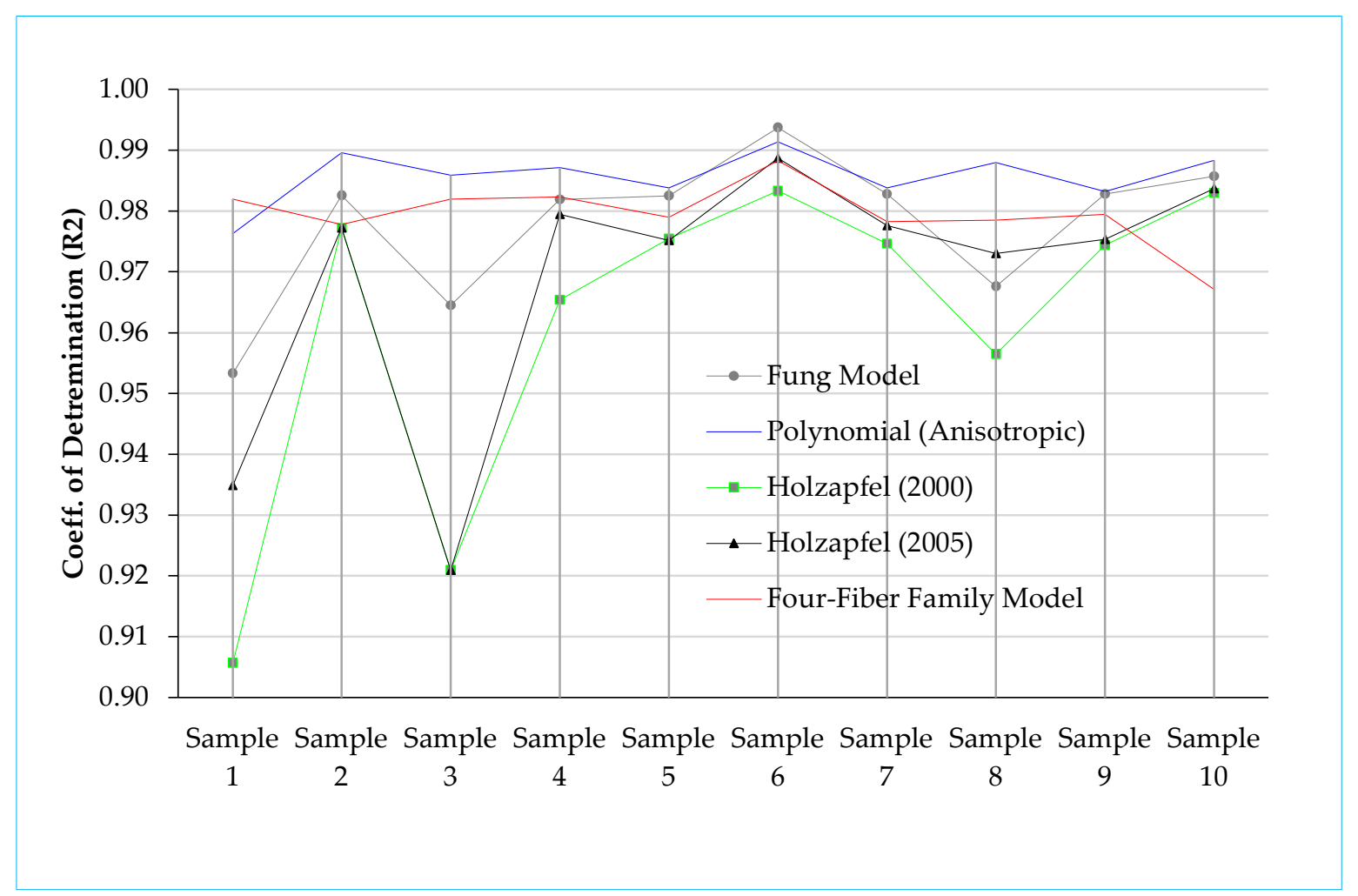

Figure 8: Fitting of various constitutive models with resulting coefficient of determination $\left(R^{2}\right)$ showing the Polynomial (Anisotropic) Model with a best fit. 


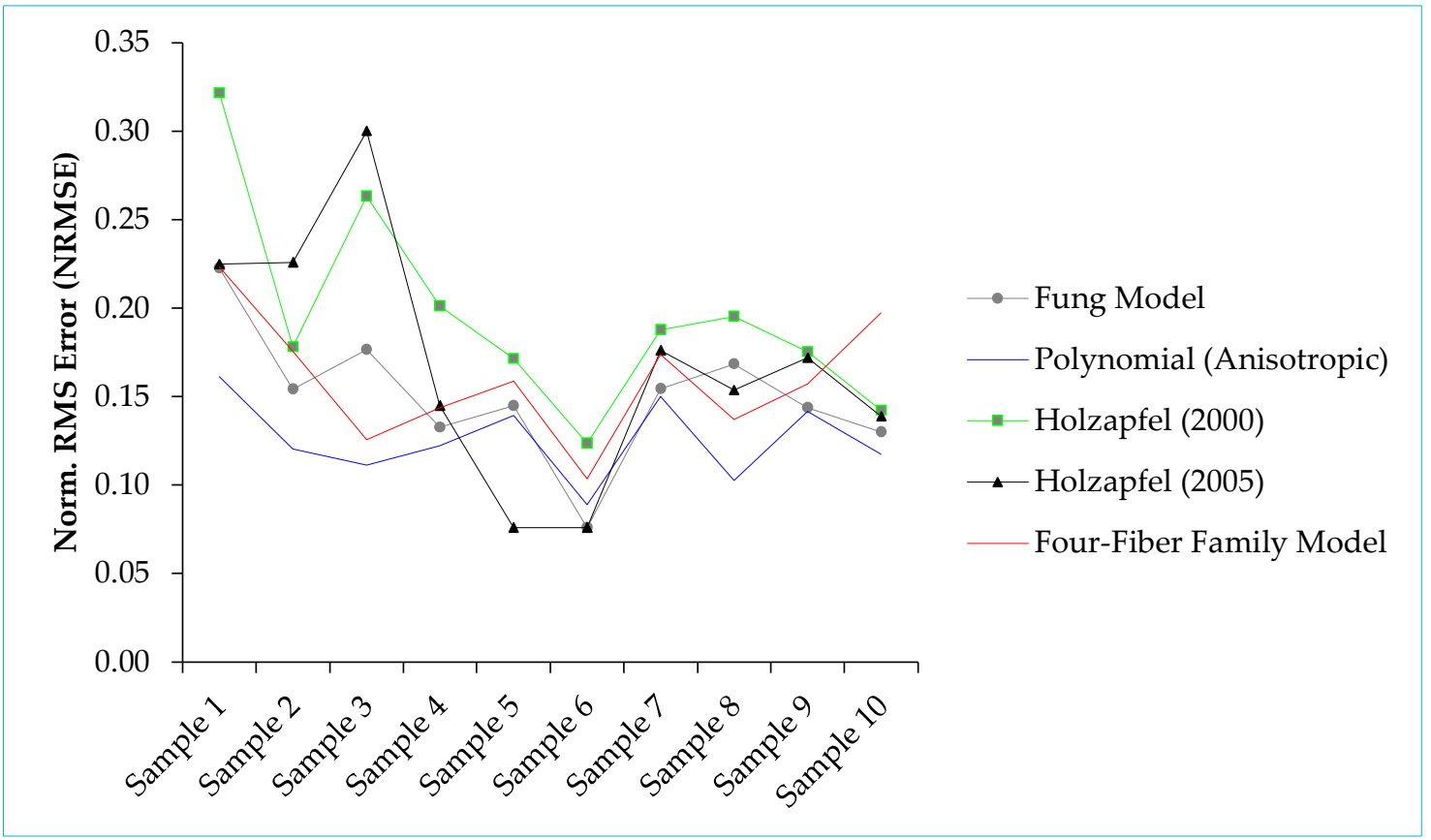

Figure 9: Fitting of various constitutive models with resulting Norm. RMS Error showing the Polynomial (Anisotropic) Model with the lowest value of the Norm. RMS Error.

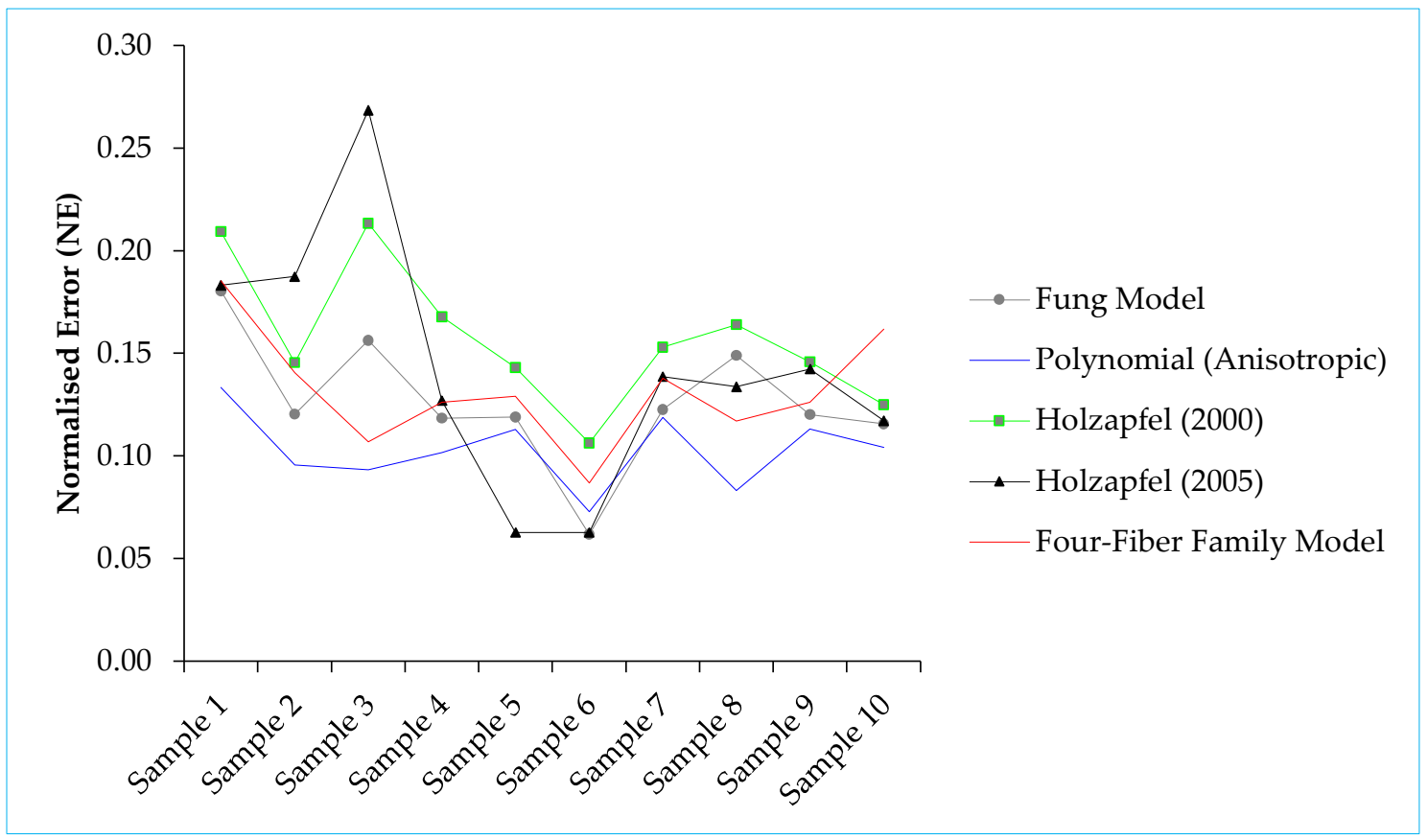

Figure 10: Fitting of various constitutive models with resulting Normalised error of the Fung, Polynomial (Anisotropic), Holzapfel (2000), Holzapfel (2005) and Four-fibre Family hyperelastic models. The Polynomial (Anisotropic) hyperelastic model has the lowest value of the Normalised Error. 


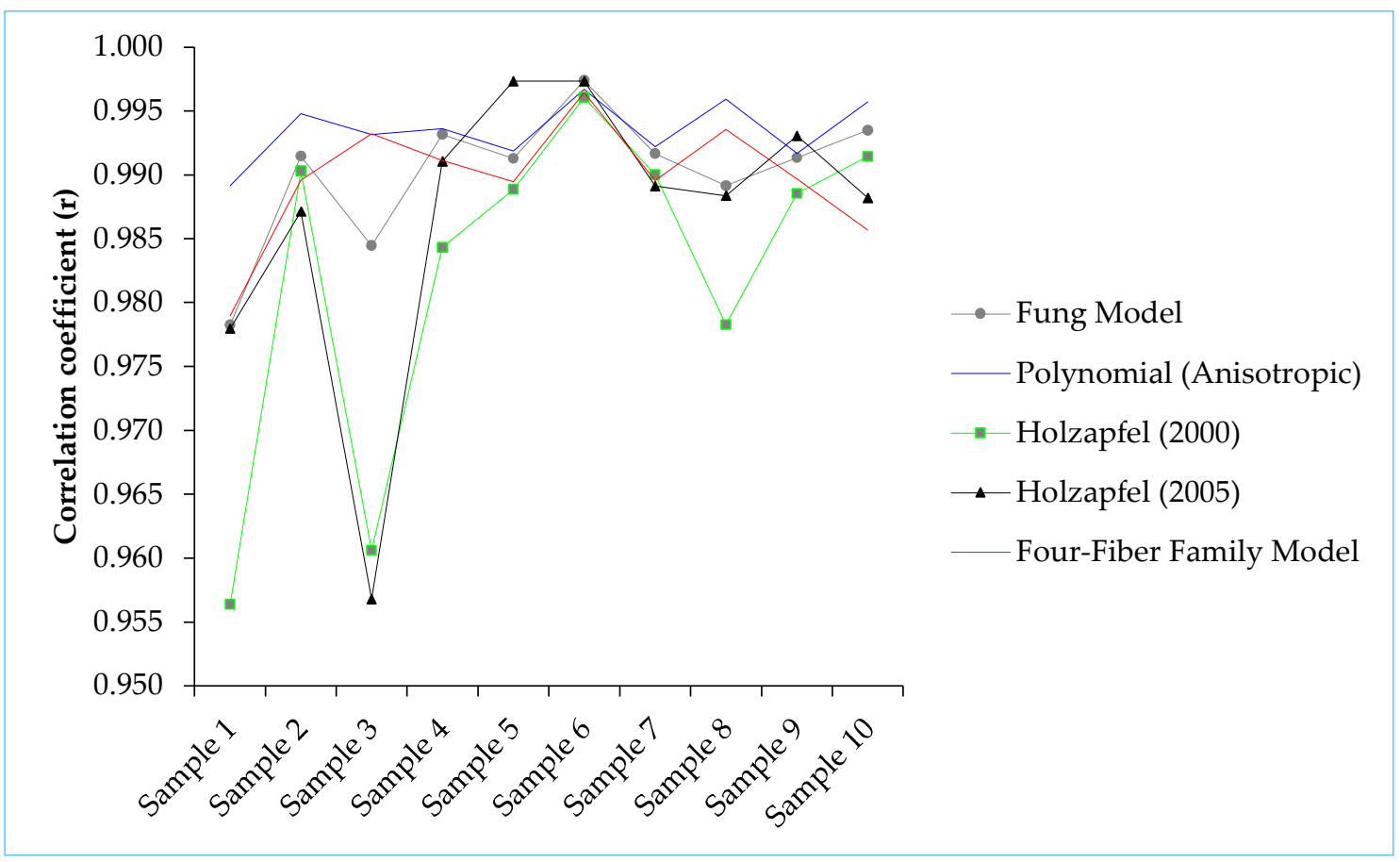

Figure 11: Fitting of various constitutive models with resulting Correlation coefficient of the Fung, Polynomial (Anisotropic), Holzapfel (2000), Holzapfel (2005) and Four-Family hyperelastic models. The Polynomial (Anisotropic) hyperelastic model has the highest value of the Correlation coefficient.

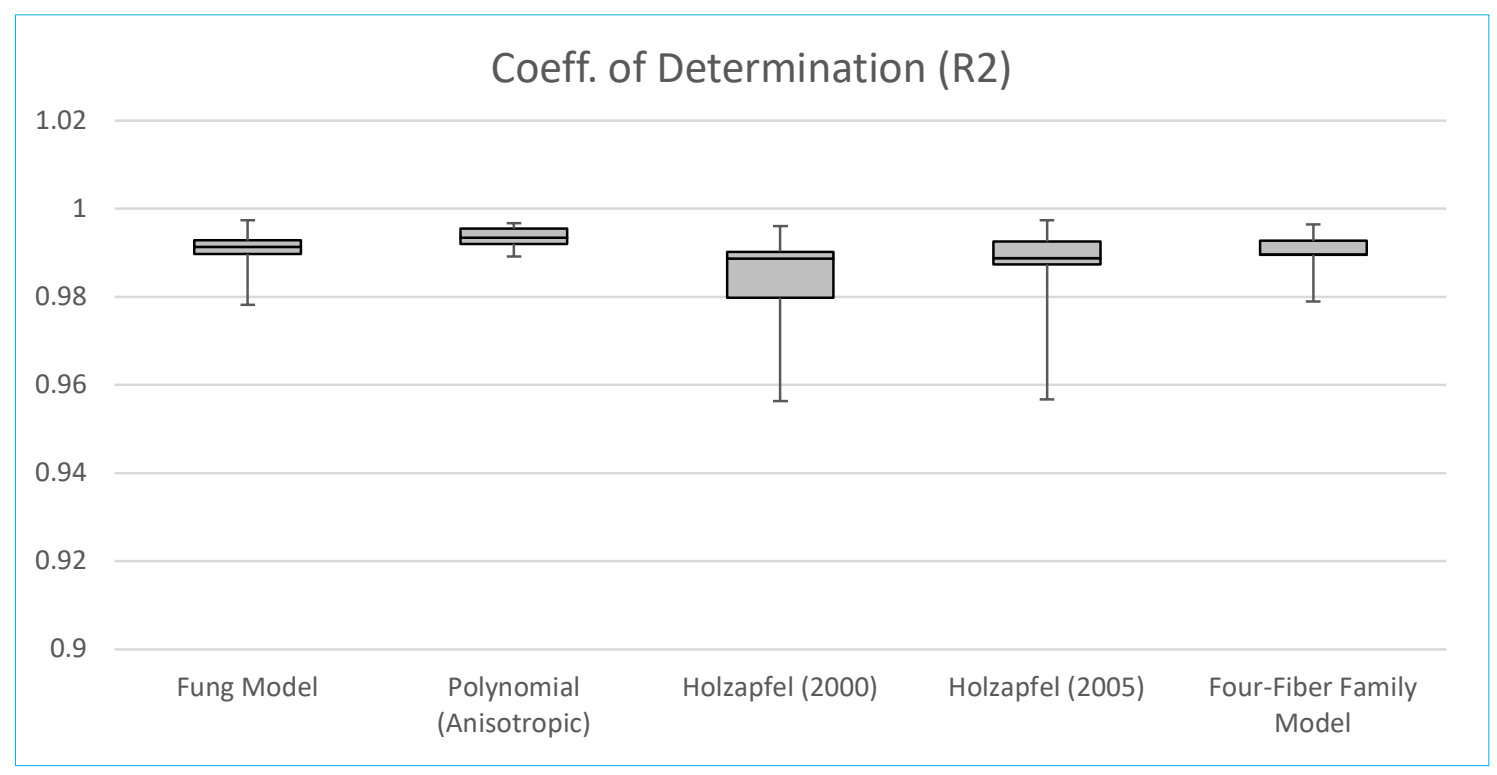

Figure 12: Box Plot comparing the median (solid line) and the spread (maximum and minimum) (grey-shaded area) of the absolute percentage errors of the average of the Coefficient of Determination $\left(R^{2}\right)$ for all hyperelastic constitutive models (Fung model, Polynomial (Anisotropic) Model, Holzapfel (2000) Model, Holzapfel (2005) Model and Four-fibre Family Model) computed by fitting the engineering stress and strain in the constitutive equations. 


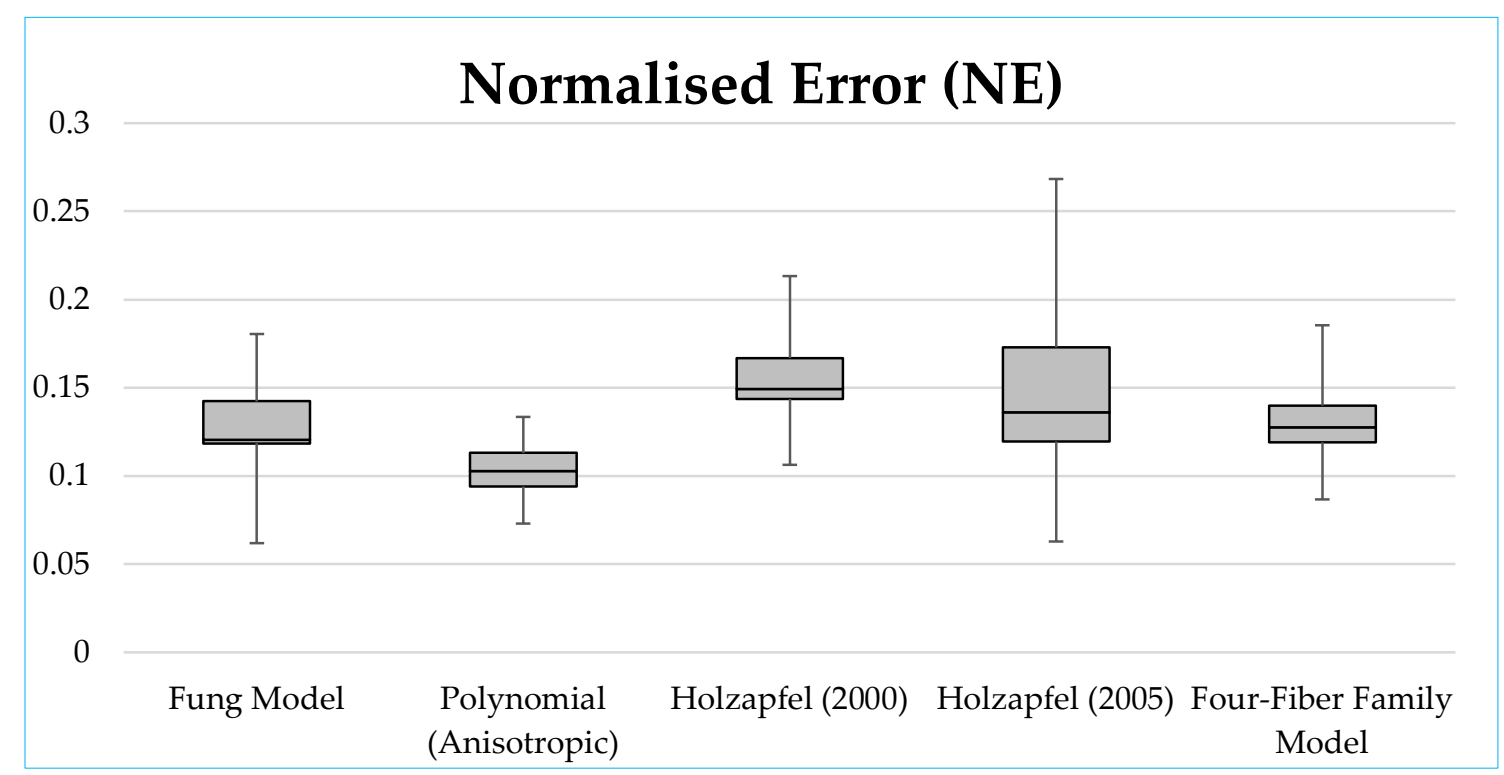

Figure 13: Box Plot comparing the median (solid line) and the spread (maximum and minimum) (grey-shaded area) of the absolute percentage errors of the average of the Normalised Error (NE) for all hyperelastic constitutive models (Fung model, Polynomial (anisotropic) Model, Holzapfel (2000) Model, Holzapfel (2005) Model and Four-fibre Family Model) computed by fitting the engineering stress and strain in the constitutive equations.

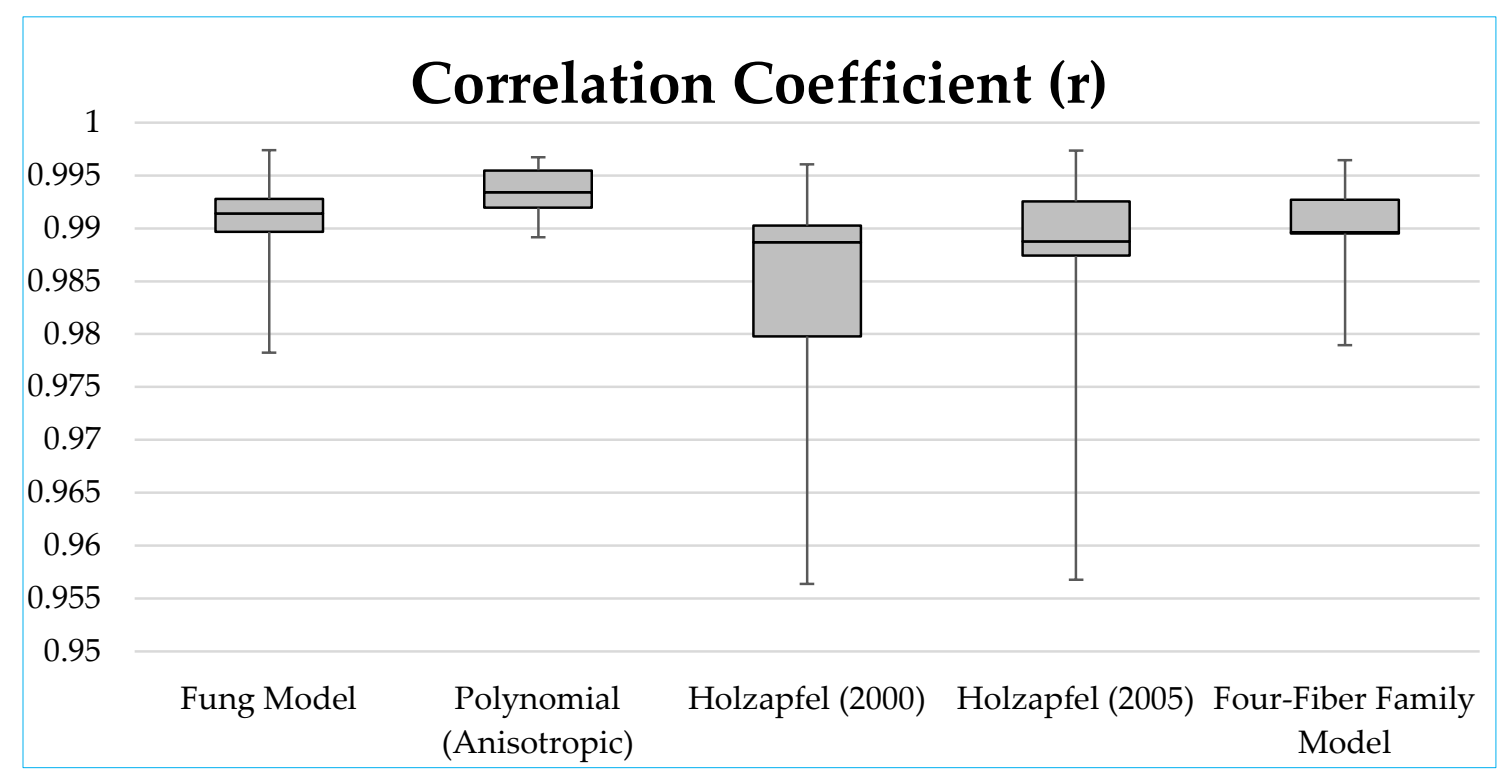

Figure 14: Box Plot comparing the median (solid line) and the spread (maximum and minimum) (grey-shaded area) of the absolute percentage errors of the average of the Correlation Coefficient ( $\mathrm{r}$ ) for all hyperelastic constitutive models

(Fung model, Polynomial (Anisotropic) Model, Holzapfel (2000) Model, Holzapfel (2005) Model and Four-fibre Family Model) computed by fitting the engineering stress and strain in the constitutive equations. 


\section{Discussion}

\subsection{Overall findings}

Global function of the heart depends mainly on the mechanical properties of cardiac tissue. The goal of this study is to determine the best hyperelastic constitutive models plotted in stress-strain curves from the uniaxial test data $(\mathrm{N}=10)$ of the sheep fibre. The results of the uniaxial tension tests of sheep heart fibre on the LV of the myocardium tissue are presented. The results of the stress-strain curve is in line with what has been presented in the literature $[26,27]$. All the heart fibre tissue exhibited a distinct hyperelastic and nonlinear mechanical behaviour, with the main features being the exponential shape of the stress-strain curves. The stress-strain response uniaxial data of LV sheep fibre was utilised to fit in the strain energy functions of the Fung, Polynomial (Anisotropic), Holzapfel (2005), Holzapfel (2000) and Four-fibre Family model. A direct comparison of hyperelastic constitutive models was made based on correlation coefficient (R2) and evaluation index (EI).

The mechanical response of the myocardium is vital in understanding the mechanisms of cardiovascular-related diseases and possible understanding of how therapies can be developed and administered. Currently, there is massive development of powerful computers that could be utilised for complex development finite element analysis and hyper numerical techniques. Accurate results based on computational analysis of the stress and strain will mainly depend on the high accuracy and reliable hyperelastic constitutive models.

It was found that the Polynomial (Anisotropic) model is better than all the other constitutive models based on the average high correlation coefficient $\left(R^{2}\right)$ of 0.99 . In this paper, the average correlation coefficient was utilised as a deciding factor, however, it is reported that averaging the stress-strain curve is the best option [28]. It has been observed that the average correlation coefficient $\left(R^{2}\right)$ of experimental fitted data may not reproduce average hyperelastic constitutive model. Also, the individual correlation coefficient $\left(R^{2}\right)$ generated from each sample (from $\mathrm{N}=10$ ) fitted in five hyperelastic models was compared. This approach may assist in coming to the right conclusion since the plotted trend of selected constitutive models for each $\mathrm{R}^{2}$.

To fully characterise the mechanical response of the cardiac tissue biaxial testing is normally utilised [3, 7]. However, in order to capture anisotropic mechanical response non-linear the shear tests are also required [16, 29]. In this paper only uniaxial experimental data was utilised to fit the strain energy of various constitutive models. Even though this model may not fully characterise the mechanical response of the cardiac tissue of the LV of the sheep, enough evidence may be obtained on how best the constitutive model fitted the selected constitutive models. This is mainly because the material parameters obtained from fitting the strain energy of hyperelastic constitutive models may be directly utilised in developing computational models [8-14].

The mechanical uniaxial data of the heart fibre was fitted into four constitutive models to better characterise the underlying mechanics of the tissue. Soft tissue like the myocardium shows distinctive mechanical properties such as elasticity, viscoelasticity, 
and so on. These properties are vital to ensure that the heart can perform its mechanical function without fail.

It was observed that there is a significant difference $(p<0.05)$ between the thickness and the width of the LV fibre dimensions. The reported longitudinal stress in the region of between 40 and $50 \mathrm{kPa}$ is similar to what has been reported in the literature [26, 27]. The typical stress-strain curves $(\mathrm{N}=10)$ were fitted with all hyperelastic constitutive models shown in Equations (6), (8), (12), (15) and (20).

Lastly, it is observed that the full characterisation of the mechanical behaviour of the heart myocardium requires both biaxial and shear test. Anisotropic behaviour may also be fully understood by utilising inverse finite element modelling [8, 9, 30]. In conclusion, stress-strain curves were utilised to exhibit the mechanical behaviour of the LV fibre of the sheep. All the specimens subjected to uniaxial load have shown non-linear response of stress and strain. The Polynomial (Anisotropic) hyperelastic constitutive model was found to have the EI of 100 . This means that it is the best performance constitutive model when compared to the other four hyperelastic models considered in this study. In addition, the Four-fibre Family hyperelastic constitutive model was found to have the EI of 63 and is therefore regarded as second best in terms of performance when fitted on the uniaxial experimental data of the sheep heart fibre. Finally, the worst performer with EI of 0 was found to be the Holzapfel (2000) model.

\subsection{Study limitations and future extensions}

Determination of the mechanical properties of the sheep heart fibre on the LV of the myocardium tissue is based not only on the distribution and orientation of fibre tissue elements but also on collagen orientation, which was not investigated here. Hence, continued research is required to identify the related mechanics of tissue collagen orientation. In addition, a relatively small number $(\mathrm{N}=10)$ of heart tissue samples were investigated, so a meaningful correlation between biomechanical properties of the different heart fibre tissue could not be quantified. Uniaxial and biaxial mechanical tests are the most common methods to investigate mechanical properties of sheep heart fibre. While the uniaxial mechanical test offers a quicker and easier examination of the material mechanical property, the biaxial mechanical test better mimics the loading conditions. Hence, additional tests should be conducted with the biaxial testing system to determine the biaxial properties to expand the present data. Composition of the sheep heart fibre specimens may also vary throughout their dimension due physiological differences such as the myocardial structure, morphology, and underlying heart conditions and this was not investigated during the study. Future studies should characterise the important aspect of viscoelastic properties LV under different physiological conditions.

\subsection{Conclusion}

A critical issue in cardiovascular solid mechanics is the determination of the mechanical properties of various tissues under various loading conditions. Depending on the desired mechanical response to be measured, the tests can be conducted as uniaxial or 
biaxial. Uniaxial mechanical tests results conducted on the sheep heart fibre tissue were fitted to five hyperelastic models dissected from the LV. The Polynomial (Anisotropic) model has the EI of 100 and this means that it is the best performance when compared to all the others. The Four-fibre family model has the EI of 63 and is therefore regarded as number two in terms of performances when fitted on the uniaxial experimental data of the sheep heart fibre. The worse performer with EI of 0 is the Holzapfel (2000) model. The best hyperelastic model for the sheep fibre myocardium under uniaxial loading was found to be the Polynomial (Anisotropic) model. This model is stable when performing iteration and yielded an average of coefficient of determination $\left(R^{2}\right)$ of 0.99 . The three average hyperelastic models are Fung and Four-fibre Family and Holzapfel (2005) that have registered an average of coefficient of determination $\left(R^{2}\right)$ of $0.98,0.98$ and 0.97, respectively. The Holzapfel (2000) hyperelastic model was found to be the least performing due to the low average of coefficient of determination $\left(\mathrm{R}^{2}\right)$ of 0.96 .

Mechanical properties of the myocardial tissues play an important role in the development of computational models to study various mechanisms of heart diseases. This experimental work provides a comprehensive collection of data for the passive mechanical properties of sheep heart fibre from LV. These material parameters could be confidently utilised in the future for development of Finite Element Models (FEM) in understanding how myocardial infarction affects the global functioning of the heart. Good mechanical properties of the heart region can lead to improved interventions and therapies from knowledge gained from FEM models.

\section{Conflicts of interest}

The authors of this paper have no financial or personal relationships with other people or organisations that could inappropriately influence (bias) our work.

\section{Acknowledgments}

Support from the National Research Foundation (NRF) Grant number (129380) is gratefully acknowledged. The Unisa CAPEX Programme supported the acquisition of a biaxial testing machine in the Department of Mechanical Engineering, School of Engineering, College of Science Engineering and Technology. We also acknowledge graduate researchers Lebogang Lebea and Lebogang Mathebela, for their assistance with the biaxial mechanical testing.

\section{References}

1. Ndlovu, Z., F. Nemavhola, and D. Desai, BIAXIAL MECHANICAL CHARACTERIZATION AND CONSTITUTIVE MODELLING OF SHEEP SCLERA SOFT TISSUE. Russian Journal of Biomechanics/Rossijski Zurnal Biomehaniki, 2020. 24(1).

2. Ngwangwa, H.M. and F. Nemavhola, Evaluating computational performances of hyperelastic models on supraspinatus tendon uniaxial tensile test data. Journal of Computational Applied Mechanics, 2021. 52(1): p. 2743. 
3. Nemavhola, F., Biaxial quantification of passive porcine myocardium elastic properties by region. Engineering Solid Mechanics, 2017. 5(3): p. 155-166.

4. Ndlovu, Z., et al., Sheep Sclera Soft Tissue Subjected to Mechanical Equi-Biaxial Testing. Preprints, 2021. 2021080388.

5. Ngwangwa, H.M., T. Pandelani, and F. Nemavhola, The Application of Standard Nonlinear Solid Material Models in Modelling the Tensile Behaviour of the Supraspinatus Tendon. Preprints, 2021. 2021080298.

6. Nemavhola, F., et al., Passive Biaxial Tensile Dataset of Three Main Rat Heart Myocardia: Left Ventricle, Mid-Wall and Right Ventricle. Preprints, 2021. 2021080153(Version 1).

7. Nemavhola, F., Study of biaxial mechanical properties of the passive pig heart: material characterisation and categorisation of regional differences. International Journal of Mechanical and Materials Engineering, 2021. 16(1): p. 1-14.

8. Nemavhola, F., Detailed structural assessment of healthy interventricular septum in the presence of remodeling infarct in the free wall-A finite element model. Heliyon, 2019. 5(6): p. e01841.

9. Nemavhola, F., Fibrotic infarction on the LV free wall may alter the mechanics of healthy septal wall during passive filling. Bio-medical materials and engineering, 2017. 28(6): p. 579-599.

10. Nemavhola, F., Mechanics of the septal wall may be affected by the presence of fibrotic infarct in the free wall at endsystole. International Journal of Medical Engineering and Informatics, 2019. 11(3): p. 205-225.

11. Masithulela, F., Bi-ventricular finite element model of right ventricle overload in the healthy rat heart. Bio-medical materials and engineering, 2016. 27(5): p. 507-525.

12. Masithulela, F. The effect of over-loaded right ventricle during passive filling in rat heart: A biventricular finite element model. in ASME International Mechanical Engineering Congress and Exposition. 2015. American Society of Mechanical Engineers.

13. Masithulela, F. Analysis of passive filling with fibrotic myocardial infarction. in ASME international mechanical engineering congress and exposition. 2015. American Society of Mechanical Engineers.

14. Masithulela, F.J., Computational biomechanics in the remodelling rat heart post myocardial infarction. 2016.

15. Avazmohammadi, R., et al., A contemporary look at biomechanical models of myocardium. Annual review of biomedical engineering, 2019. 21: p. 417-442.

16. Holzapfel, G.A. and R.W. Ogden, Constitutive modelling of passive myocardium: a structurally based framework for material characterization. Philosophical Transactions of the Royal Society A: Mathematical, Physical and Engineering Sciences, 2009. 367(1902): p. 3445-3475.

17. Jiang, M., et al., A versatile biaxial testing platform for soft tissues. Journal of the Mechanical Behavior of Biomedical Materials, 2021. 114: p. 104144.

18. Lu, T., et al., A micro-structure based constitutive model for anisotropic stress-strain behaviors of artery tissues. International Journal of Solids and Structures, 2018. 139: p. 55-64.

19. He, H., et al., A comparative study of 85 hyperelastic constitutive models for both unfilled rubber and highly filled rubber nanocomposite material. Nano Materials Science, 2021.

20. de Bortoli, D., et al. Hyperfit-curve fitting software for incompressible hyperelastic material models. in Proceedings of COBEM. 2011.

21. Chuong, C. and Y. Fung, Three-dimensional stress distribution in arteries. Journal of biomechanical engineering, 1983. 105(3): p. 268-274.

22. Holzapfel, G.A., T.C. Gasser, and R.W. Ogden, A new constitutive framework for arterial wall mechanics and a comparative study of material models. Journal of elasticity and the physical science of solids, 2000. 61(1): p. 1-48. 
23. Holzapfel, G.A., et al., Determination of layer-specific mechanical properties of human coronary arteries with nonatherosclerotic intimal thickening and related constitutive modeling. American Journal of Physiology-Heart and Circulatory Physiology, 2005. 289(5): p. H2048-H2058.

24. Ferruzzi, J., D.A. Vorp, and J. Humphrey, On constitutive descriptors of the biaxial mechanical behaviour of human abdominal aorta and aneurysms. Journal of the Royal Society Interface, 2011. 8(56): p. 435-450.

25. Baek, S., et al., Theory of small on large: potential utility in computations of fluid-solid interactions in arteries. Computer methods in applied mechanics and engineering, 2007. 196(31-32): p. 3070-3078.

26. Gupta, K.B., et al., Changes in passive mechanical stiffness of myocardial tissue with aneurysm formation. Circulation, 1994. 89(5): p. 2315-2326.

27. Javani, S., M. Gordon, and A.N. Azadani, Biomechanical properties and microstructure of heart chambers: A paired comparison study in an ovine model. Annals of biomedical engineering, 2016. 44(11): p. 3266-3283.

28. Robertson, D. and D. Cook, Unrealistic statistics: how average constitutive coefficients can produce non-physical results. Journal of the mechanical behavior of biomedical materials, 2014. 40: p. 234-239.

29. Sommer, G., et al., Biomechanical properties and microstructure of human ventricular myocardium. Acta biomaterialia, 2015. 24: p. 172-192.

30. Nikou, A., et al., Computational modeling of healthy myocardium in diastole. Annals of biomedical engineering, 2016. 44(4): p. 980-992. 